1996

\title{
Biogenic Matter Diagenesis on the Sea Floor: A Comparison Between Two Continental Margin Transects
}

\author{
William M. Berelson \\ Jim McManus \\ Kenneth H. Coale \\ Kenneth S. Johnson \\ Tammy Kilgore
}

See next page for additional authors

Follow this and additional works at: https://digitalcommons.odu.edu/oeas_fac_pubs

Part of the Biogeochemistry Commons, and the Oceanography Commons

\section{Repository Citation}

Berelson, William M.; McManus, Jim; Coale, Kenneth H.; Johnson, Kenneth S.; Kilgore, Tammy; Burdige, David J.; and Pilskaln, Cynthia, "Biogenic Matter Diagenesis on the Sea Floor: A Comparison Between Two Continental Margin Transects" (1996). OEAS Faculty Publications. 138.

https://digitalcommons.odu.edu/oeas_fac_pubs/138

\section{Original Publication Citation}

Berelson, W.M., McManus, J., Coale, K.H., Johnson, K.S., Kilgore, T., Burdige, D., \& Pilskaln, C. (1996). Biogenic matter diagenesis on the sea floor: A comparison between two continental margin transects. Journal of Marine Research, 54(4), 731-762. doi: 10.1357/ 0022240963213673 
Authors

William M. Berelson, Jim McManus, Kenneth H. Coale, Kenneth S. Johnson, Tammy Kilgore, David J.

Burdige, and Cynthia Pilskaln 


\title{
Biogenic matter diagenesis on the sea floor: A comparison between two continental margin transects
}

\author{
by William M. Berelson ${ }^{1}$, Jim McManus ${ }^{1}$, Kenneth H. Coale ${ }^{2}$, Kenneth S. Johnson ${ }^{2}$, \\ Tammy Kilgore ${ }^{1}$, David Burdige ${ }^{3}$ and Cynthia Pilskaln ${ }^{4}$
}

\begin{abstract}
Benthic chamber measurements of the reactants and products involved with biogenic matter diagenesis (oxygen, ammonium, nitrate, silicate, phosphate, $\mathrm{TCO}_{2}$, alkalinity) were used to define fluxes of these solutes into and out of the sediments off southern and central California. Onshore to offshore transects indicate many similarities in benthic fluxes between these regions. The pattern of benthic organic carbon oxidation as a function of water depth, combined with published sediment trap records, suggest that the supply of organic carbon from vertical rain can just meet the sedimentary carbon oxidation + burial demand for the central California region between the depths $100-3500 \mathrm{~m}$. However, there is not enough organic carbon raining through the upper water column to support its oxidation and burial in the basins off southern California. Lateral transport and focusing of refractory carbon within these basins is proposed to account for the carbon buried. The organic carbon burial efficiency is greater off southern California (40-60\%) compared to central California (2-20\%), even though carbon rain rates are comparable. Oxygen uptake rates are not sensitive to bottom water oxygen concentrations nor to the bulk wt. \% organic carbon in surficial sediments. Nitrate uptake rates are well defined by the depth of oxygen penetration into the sediments and the overlying water column nitrate concentration. Nitrate uptake accounts for about $50 \%$ of the total denitrification taking place in shelf sediments and denitrification $\left(0.1-1.0 \mathrm{mmolN} / \mathrm{m}^{2} \mathrm{~d}\right)$ occurs throughout the entire study region. The ratio of carbon oxidized to opal dissolved on the sea fioor is constant $(0.8 \pm 0.2)$ through a wide range of depths, supporting the hypothesis that opal dissolution kinetics may be dominated by a highly reactive phase. Sea foor carbonate dissolution is negligible within the oxygen minimum zone and reaches maximal rates just above and below this zone $\left(0.2-2.0 \mathrm{mmol} / \mathrm{m}^{2} \mathrm{~d}\right)$.
\end{abstract}

\section{Introduction}

The rate of biogenic matter recycling at the sediment-water interface is indicative of the reactivity and quantity of material raining from the upper ocean and of biogeochemical conditions within the sediment column. Benthic recycling also defines the degree to which the geologic record reflects the input of fresh material. Continental margin sediments are

1. Department of Earth Sciences, University of Southern California, Los Angeles, California, 90089-0740, U.S.A.

2. Moss Landing Marine Laboratories, P.O. Box 450, Moss Landing, California, 95039, U.S.A.

3. Department of Oceanography, Old Dominion University, Norfolk, Virginia, 23529, U.S.A.

4. Department of Oceanography, University of Maine, Orono, Maine 04469, U.S.A. 
particularly important regions of benthic recycling because they comprise a significant component of the global budgets for organic carbon burial (Reimers et al., 1992), oxygen consumption (Jahnke and Jackson, 1987), denitrification (Christensen et al., 1987) and biogenic silica burial (Treguer et al., 1995). In this paper we attempt to balance the budget for carbon flux between the water column, sediment recycling and burial within continental margin systems (Jahnke et al., 1990; Reimers et al., 1992; Biscaye et al., 1994). We also investigate the conditions that favor organic carbon burial, dissolution of biogenic silica and calcium carbonate, and the recycling of nitrogen.

We have made measurements of benthic exchange rates of a number of the products and reactants involved in biogenic material diagenesis utilizing a benthic chamber. Two field areas, the central and southern California margins, were investigated with chamber deployments in a transect from nearshore $(100 \mathrm{~m})$ to offshore $(3700 \mathrm{~m})$. Both study regions cross through the oxygen minimum zone, thus we determined diagenetic rates and reactions occurring under a range of depths and bottom water oxygen concentrations.

Benthic chambers, which incubate sediment in situ, integrate the net transport of solutes between pore waters and the overlying water. An important benefit of using chambers is the integrated view of diagenesis developed when many parameters are measured. Fluxes may be calculated directly from changes in chamber concentration, which is important in settings where near-surface chemical gradients are very steep and not easily sampled using pore water extraction methods or where solute transport is nondiffusive. Although chamber measurements do not directly indicate the depth of reaction within sediments, this information can be extracted from net flux data and modeling.

One purpose of this study was to compare two margin settings and ascertain if biogenic matter recycling could be generalized and described by simple models. Further, we attempt to measure the degree of spatial and temporal variability in recycling rates. Temporal variability may indicate reaction kinetics responsive on a time scale of $<1$ year, the spacing between cruises. The coupling between particulate rain and biogeochemical reaction on the sea floor is important with respect to chemical budgets and should define the methods appropriate for study of benthic fluxes. Two studies that combined sediment trap and benthic chamber measurements of organic carbon fluxes found very different degrees of coupling between rain and benthic reaction (Smith et al., 1992; Sayles et al., 1994). In view of these results, we made flux measurements in regions previously studied with benthic chambers (Berelson et al., 1986, 1987a; Smith, 1987; Smith et al., 1992, 1994; Bender et al., 1989; Jahnke, 1990; Jahnke et al., 1990; Reimers et al., 1992) and where there have been extensive sediment trap deployments (Martin et al., 1987; Smith, 1987; Smith et al., 1994; Eganhouse and Venkatesan, 1993; Thunell et al., 1994; Pilskaln et al., 1996). Although sediment traps were not located within both study regions during the time period covered by chamber measurements, we are able to compare previous trap data and surface ocean productivity proxies with measurements of benthic recycling. In this paper we examine the relationship between organic carbon degradation, biogenic silica and calcium carbonate dissolution, and the flux of oxygen, nitrate, ammonia and phosphate. 


\section{Methods}

The transects of benthic chamber deployments (Fig. 1 and Table 1) included stations in the central California region (CC) which were occupied during two cruise periods (CC I in June, 1991 and CC II in May, 1992), and 6 southern California sites (Basins) which were occupied in March, 1994. At each station, 1 or 2 USC Landers (Berelson and Hammond, 1986) were deployed as free vehicles, and the sediment beneath each of the devices' 3 chambers was incubated for 12-72 hours. Chamber water was gently stirred with a rotating paddle to develop a $400 \mu \mathrm{m}$ thick diffusive boundary layer within the chamber (Berelson $e t$ al., 1990). During incubation, 6 samples were withdrawn from the chamber, transporting 200-300 $\mathrm{ml}$ of chamber water through Teflon tubing, polypropylene, and glass sample tubes, displacing an equal volume of de-ionized water. Ambient bottom water was allowed to replace the sample withdrawn by exchange through a capillary tube.

A $45 \mathrm{ml}$ sample was split for analysis of trace metals (Johnson et al., 1992) and nutrients (silicate, nitrate + nitrite, phosphate, ammonia), $\mathrm{pH}$, alkalinity and $\mathrm{TCO}_{2}$. The nutrients were measured in replicate on filtered subsamples by auto-analyzer techniques with analytical uncertainties of $1 \%, 2.5 \%, 2 \%$, and $0.2 \mu \mathrm{M}$ respectively. Nitrite was determined to represent $<3 \%$ of the nitrate + nitrite measured and hereafter this measure is referred to as nitrate. $\mathrm{pH}$ was measured on an unfiltered split of sample using glass electrodes standardized to buffers traceable to NBS standards ( \pm 0.02 units). Alkalinity was measured in duplicate by Gran titration using $4 \mathrm{ml}$ samples. This parameter was measured to $\pm 0.3 \%$. $\mathrm{TCO}_{2}$ was measured on some cruises using a UIC 5012 coulometer on a $4 \mathrm{ml}$ sample, making replicate measurements to $\pm 0.3 \%$. $\mathrm{TCO}_{2}$ was also calculated from alkalinity and $\mathrm{pH}$ with a precision of $\pm 0.4 \%$. Where $\mathrm{TCO}_{2}$ was determined by both methods, the agreement in flux calculations was better than $30 \%$ and we report the mean flux. $\mathrm{pH}$, ammonia and $\mathrm{TCO}_{2}$ were measured within 24 hours of sample recovery, other nutrients were measured within hours to $<10$ days and alkalinity was measured within days to $<3$ weeks of sample recovery.

Oxygen tension inside and outside the chambers was monitored with a pulsed electrode (Hammond et al., 1996). The change in oxygen concentration with time was determined either from the trace of the electrode output, converted to concentration using calibrations performed in the lab and field, or from the difference in electrode output before and immediately after chamber lift-off. The second technique was necessary for some of the borderland basin deployments where oxygen concentration changes were very small (see Hammond et al., 1996 for description of this method). ${ }^{222} \mathrm{Rn}$ was measured on $100 \mathrm{ml}$ aliquots of unfiltered sample water, although these results are not reported in this paper. Conductivity was measured on all sample splits to assure that no de-ionized water remained mixed with the sample water. Conductivity was measured to $\pm 0.25 \%$ on an aliquot of $0.5 \mathrm{ml}$.

The bottom water concentration of all the parameters measured was ascertained from analysis of water collected by Niskin samples, either attached to the lander or from adjacent hydrocasts. The chamber data were corrected to account for sequential sample 


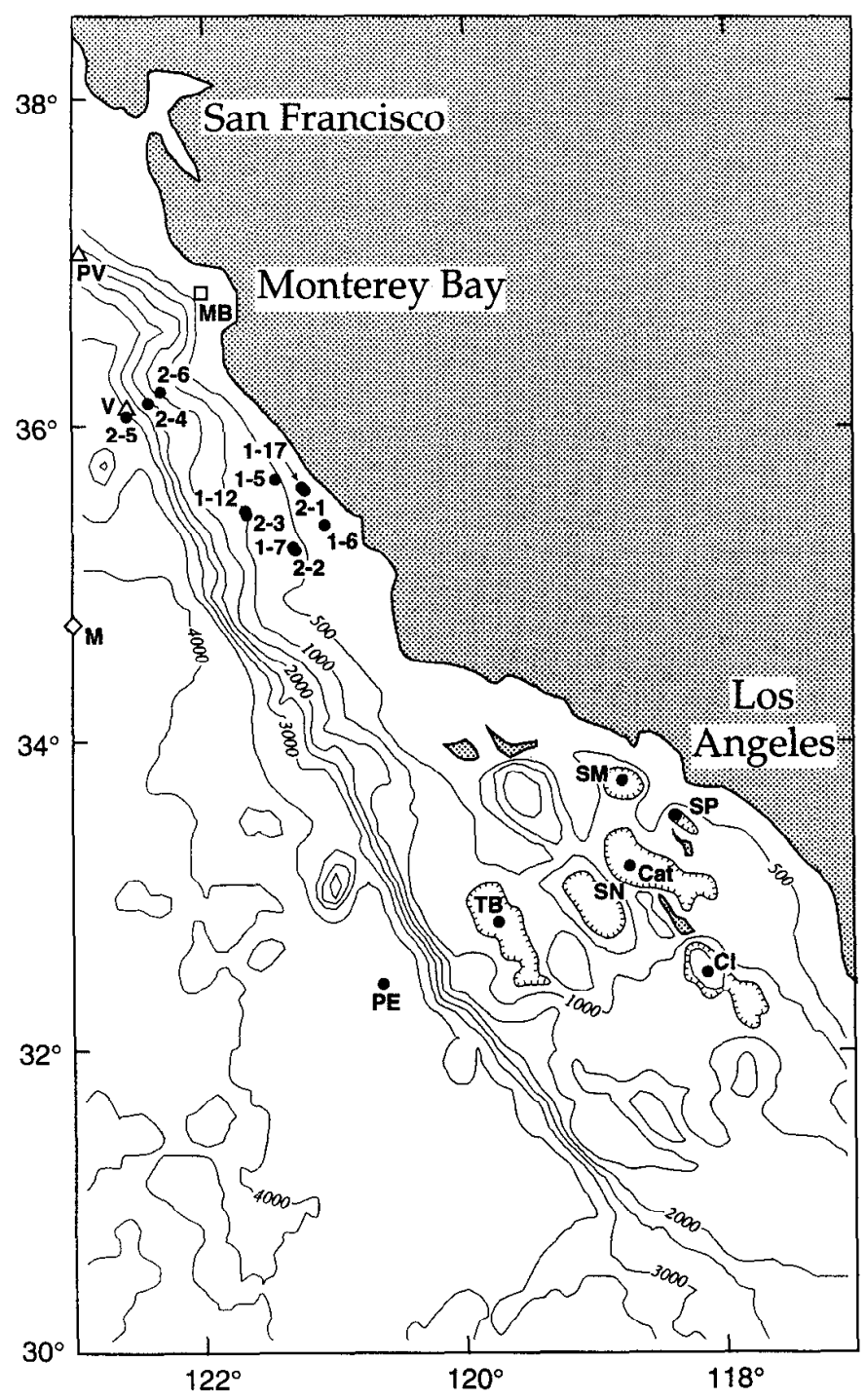

Figure 1. Study area. CC region off central California and Basins region off southern California. Station ID's correspond with Table 1 designations, the prefix 1 refers to CC I and 2 refers to CC II. In the Basins region the designations are $\mathrm{SP}=\mathrm{San}$ Pedro, $\mathrm{SM}=$ Santa Monica, $\mathrm{Cat}=$ Catalina, $\mathrm{SN}=$ San Nicolas, $\mathrm{Cl}=$ San Clemente, $\mathrm{TB}=$ Tanner and PE $=$ Patton Escarpment. $\mathrm{V}$ and PV represent locations of sediment trap deployments VERTEX 1 and PREVTX (Martin et al., 1987), MB denotes location of a sediment trap deployed in Monterey Canyon (Pilskaln et al., 1996), and the site identified as $M$ is the location of traps described by Smith et al. (1994). Depth contours are in meters. 
dilutions. Fluxes were calculated by linear regression of the corrected data as a function of incubation time and multiplying the slope by the ratio of chamber volume:area. This later parameter, effective chamber height, was determined by the dilution of a $\mathrm{CsCl}$ spike injected just before a sampling interval. Cs was measured by flame emission techniques on a $0.5 \mathrm{ml}$ aliquot to a precision of about $10 \%$. Flux uncertainties were computed to take into account the uncertainty in the linear fit, analytical uncertainties, and uncertainties in chamber height. The chamber concentration and incubation time data are available from the authors upon request.

Bottom water concentration was not used as one of the points regressed against incubation time, although the first sample drawn almost always reproduced the bottom water value to \pm 1 analytical s.d. The change in concentration of the solutes and oxygen as a function of incubation time was plotted and we omitted samples from late in the incubation sequence if the trend looked distinctly nonlinear. This could occur if chamber concentration provides a feed-back to flux rates, a phenomena modeled by Bender $e t$ al., 1989. No flux was reported if we had fewer than 4 data points. A linear fit to the chamber data presumes a constant flux during the incubation period, an approach adopted by other benthic chamber studies (Berelson and Hammond, 1986; Jahnke et al., 1990; Bender et al., 1989; Sayles et al., 1994). Some samples that may have been contaminated by de-ionized water were not included in the fit and data which appeared spurious was rejected utilizing the criteria described by Hammond et al. (1996). Where there is data from more than one chamber, all the fluxes were averaged, under equal weighting, to describe the mean flux for a site (Table 2). The uncertainty of this mean was calculated using two formulations: (1) as the standard error of the mean, and (2) as the square root of the sum of the variance of each flux value, divided by the number of flux measurements. We report the larger of these two uncertainties.

\section{Results}

a. Flux patterns. The pattern of benthic fluxes as a function of depth and cruise date demonstrate many gross similarities and a few subtle differences between research areas (Tables 1 and 2; Figs. 2 and 3). The oxygen minimum zone in both regions lies between 500 and $1500 \mathrm{~m}$ and has no influence on oxygen uptake rates, which remain constant between 700 and $3500 \mathrm{~m}$ at about $1.4 \mathrm{mmol} / \mathrm{m}^{2} \mathrm{~d}$ on the $\mathrm{CC}$ transect and about $0.7 \mathrm{mmol} / \mathrm{m}^{2} \mathrm{~d}$ in the borderland basins. Oxygen uptake on the central California shelf $(100 \mathrm{~m})$ is variable but 3-10 times greater than fluxes from sites below $1000 \mathrm{~m}$. The mean nitrate flux is into the sediments at all sites and the maximum uptake rate, about $1.2 \mathrm{mmol} / \mathrm{m}^{2} \mathrm{~d}$, is similar for both study regions and lies within the zone of lowest water column oxygen concentration. $\mathrm{TCO}_{2}$ fluxes, like oxygen uptake rates, are 3-10 times greater at the shallow stations and relatively constant at sites below $500 \mathrm{~m}$, ranging from $1.0-2.5 \mathrm{mmol} / \mathrm{m}^{2} \mathrm{~d}$ for the $\mathrm{CC}$ area and $0.5-1.5 \mathrm{mmol} / \mathrm{m}^{2} \mathrm{~d}$ off southern California.

Ammonia fluxes at sites above $500 \mathrm{~m}$ are of the same magnitude as the nitrate uptake rates. Below $700 \mathrm{~m}$, ammonia fluxes are $<0.05 \mathrm{mmol} / \mathrm{m}^{2} \mathrm{~d}$. Phosphate fluxes show the 


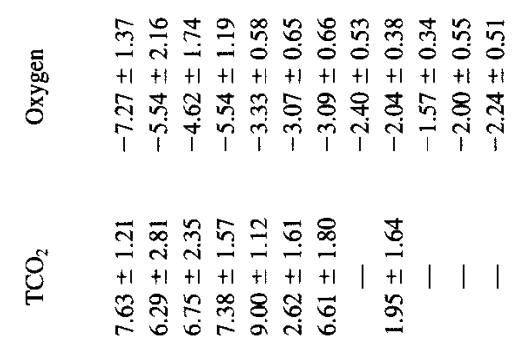

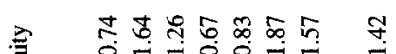
曐 $+1+1+1+1+1+1 \mid \overrightarrow{+1}$ 의

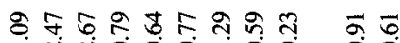
$\frac{\mathscr{6}}{\sqrt{2}}$

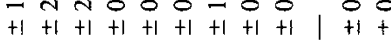

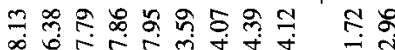

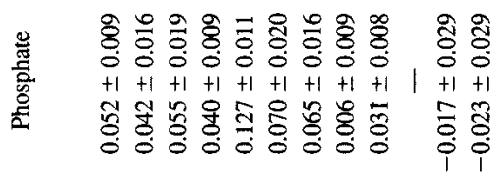

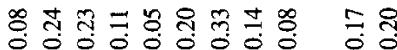

苋 $+1+1+1+1+1+1+1+1+1+1+1+$

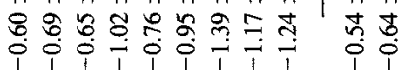

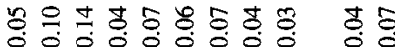

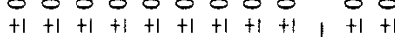

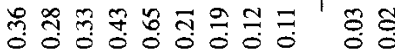

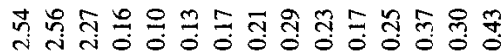
$+1+1+1+1+1+1+1+1+1+1+1+1+1+1+1$

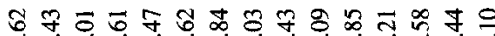

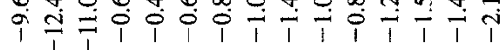

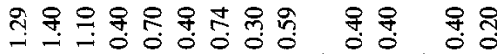
$++1+1+1+1+1+1+1+1|+1+1|+1+1$

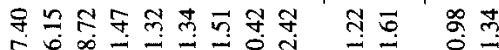

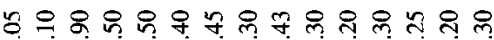
- i coo o o o o o o o o o o o $t:+1+1+1+1+1+1+1+1+1+1+1+1+1$ 의

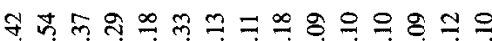

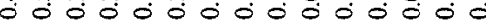
$+1+1+1+1+1+1+1+1+1+1+1+1+1+1+1$

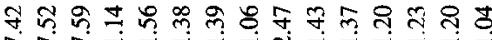

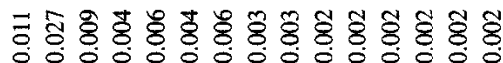
$+1+1+1+1+1+1+1+1+1+1+1+1+1+1+1$

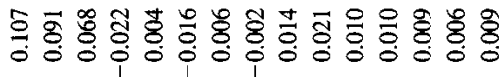

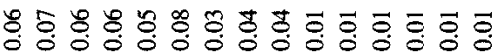
$+1+1+1+1+1+1+1+1+1+1+1+1+1+1+1$

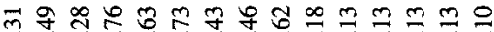

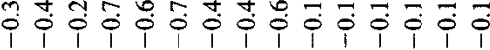

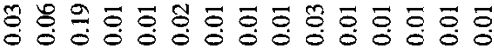
$+1+1+1+1+1+1+1+1+1+1+1+1+1+1+1$ 范苍合

๙

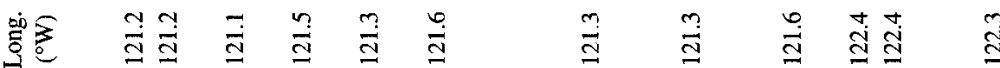

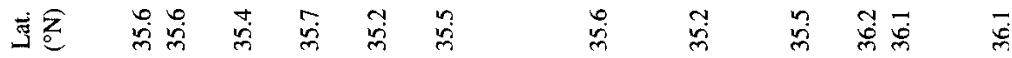

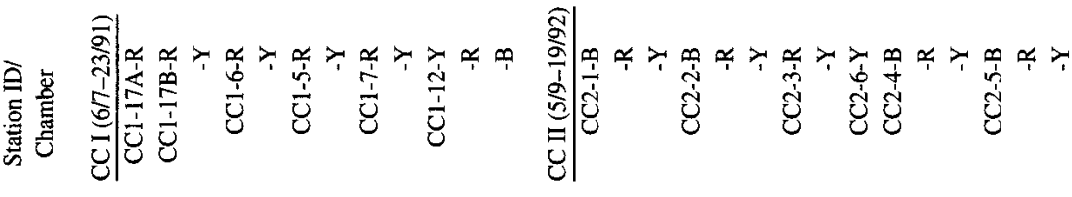




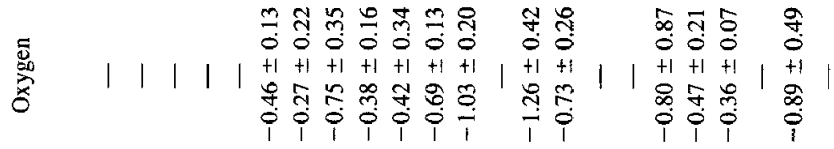

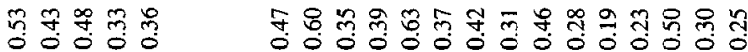
$+1+1+1+1+1|1| 1 \mid+1+1+1+1+1+1+1+1+1+1+1+1+1+1+1$

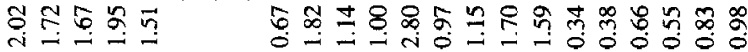

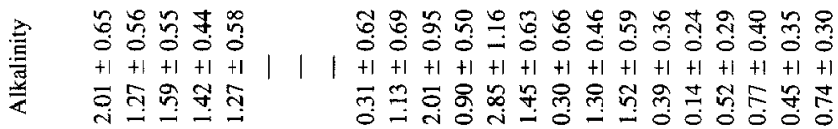

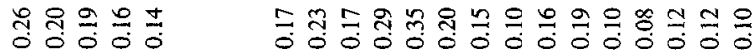

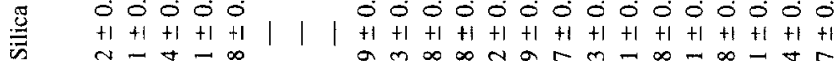

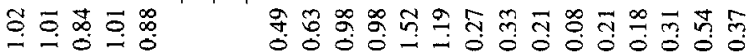

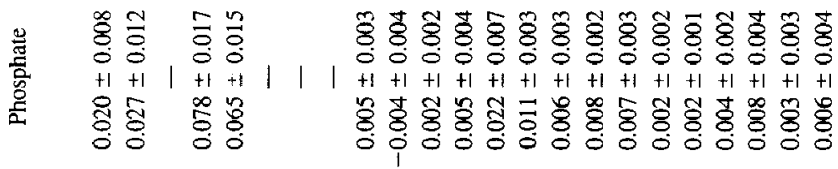

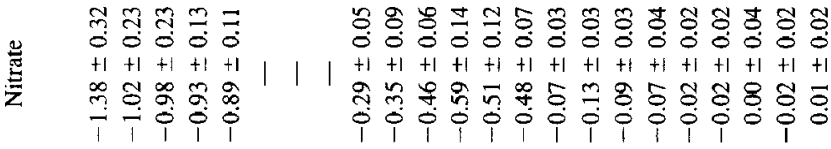

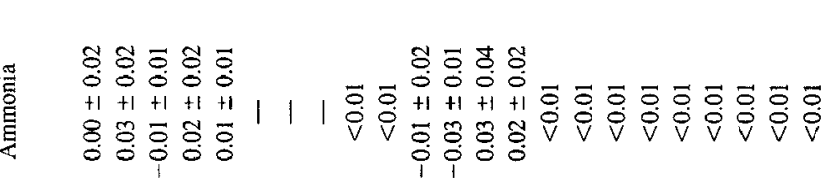

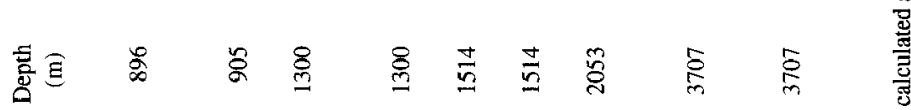

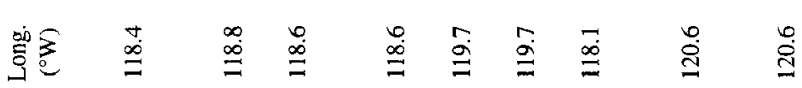

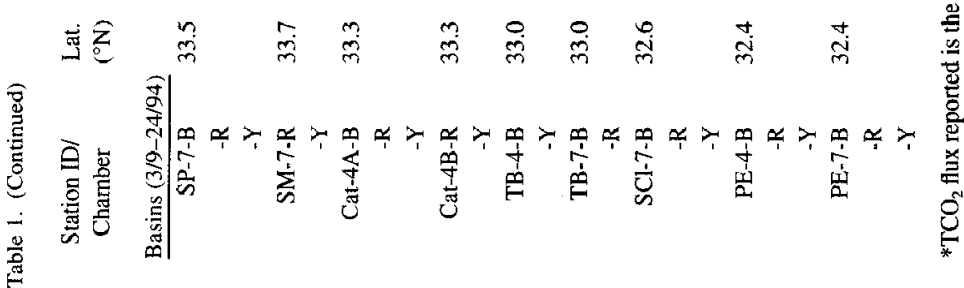


Table 2. Average lander fluxes. Fluxes in $\mathrm{mmol} / \mathrm{m}^{2} \mathrm{~d}$ except alkalinity, meq/m $\mathrm{m}^{2} \mathrm{~d}$. Uncertainties are described in the text.

\begin{tabular}{|c|c|c|c|c|c|c|c|c|}
\hline Sta. & Depth & Ammonia & Nitrate & Phosphate & Silica & Alkalinity & $\mathrm{TCO}_{2}$ & Oxygen \\
\hline \multicolumn{9}{|l|}{$\mathrm{CC} \mathrm{I}$} \\
\hline$\overline{17}$ & 95 & $0.32 \pm 0.06$ & $-0.64 \pm 0.11$ & $0.050 \pm 0.008$ & $7.43 \pm 1.20$ & $3.72 \pm 0.70$ & $6.89 \pm 1.23$ & $-5.81 \pm 1.02$ \\
\hline 6 & 231 & $0.54 \pm 0.16$ & $-0.89 \pm 0.19$ & $0.084 \pm 0.062$ & $7.90 \pm 0.51$ & $6.17 \pm 1.99$ & $8.19 \pm 1.15$ & $-4.44 \pm 1.56$ \\
\hline 5 & 532 & $0.20 \pm 0.05$ & $-1.17 \pm 0.31$ & $0.068 \pm 0.013$ & $3.83 \pm 0.73$ & $3.36 \pm 1.22$ & $4.62 \pm 2.82$ & $-3.08 \pm 0.46$ \\
\hline 7 & 638 & $0.12 \pm 0.02$ & $-1.20 \pm 0.08$ & $0.019 \pm 0.018$ & $4.26 \pm 0.29$ & $1.89 \pm 1.42$ & $1.95 \pm 1.64$ & $-2.22 \pm 0.32$ \\
\hline 12 & 1010 & $0.03 \pm 0.04$ & $-0.59 \pm 0.13$ & $-0.020 \pm 0.021$ & $2.34 \pm 0.88$ & - & - & $-1.94 \pm 0.27$ \\
\hline \multicolumn{9}{|c|}{ CC II } \\
\hline 1 & 97 & $0.59 \pm 0.14$ & $-0.36 \pm 0.08$ & $0.089 \pm 0.014$ & $7.51 \pm 0.26$ & $2.48 \pm 0.59$ & $7.42 \pm 0.91$ & $-11.02 \pm 1.42$ \\
\hline 2 & 670 & $0.02 \pm 0.01$ & $-0.71 \pm 0.05$ & $-0.011 \pm 0.010$ & $1.36 \pm 0.15$ & $1.55 \pm 0.29$ & $1.38 \pm 0.29$ & $-0.57 \pm 0.08$ \\
\hline 3 & 1010 & $0.00 \pm 0.01$ & $-0.44 \pm 0.02$ & $0.002 \pm 0.006$ & $1.22 \pm 0.23$ & $0.85 \pm 0.68$ & $0.97 \pm 0.77$ & $-0.94 \pm 0.13$ \\
\hline 6 & 1358 & $0.03 \pm 0.01$ & $-0.62 \pm 0.04$ & $0.014 \pm 0.003$ & $2.47 \pm 0.18$ & $1.96 \pm 0.43$ & $2.42 \pm 0.59$ & $-1.43 \pm 0.29$ \\
\hline 4 & 2025 & $0.00 \pm 0.01$ & $-0.15 \pm 0.02$ & $0.014 \pm 0.004$ & $1.33 \pm 0.09$ & $0.95 \pm 0.15$ & $1.42 \pm 0.28$ & $-1.05 \pm 0.13$ \\
\hline 5 & 3375 & $0.00 \pm 0.01$ & $-0.12 \pm 0.02$ & $0.008 \pm 0.002$ & $1.16 \pm 0.07$ & $1.01 \pm 0.14$ & $1.16 \pm 0.25$ & $-1.71 \pm 0.25$ \\
\hline \multicolumn{9}{|c|}{ Basins } \\
\hline$\overline{\mathrm{SP}}$ & 896 & $0.01 \pm 0.02$ & $-1.13 \pm 0.16$ & $0.024 \pm 0.007$ & $0.96 \pm 0.12$ & $1.62 \pm 0.34$ & $1.80 \pm 0.28$ & - \\
\hline SM & 905 & $0.01 \pm 0.01$ & $-0.91 \pm 0.09$ & $0.072 \pm 0.011$ & $0.95 \pm 0.11$ & $1.35 \pm 0.36$ & $1.73 \pm 0.31$ & - \\
\hline Cat & 1300 & $<0.01$ & $-0.32 \pm 0.05$ & $0.001 \pm 0.006$ & $0.56 \pm 0.14$ & $0.72 \pm 0.58$ & $1.24 \pm 0.81$ & $-0.46 \pm 0.12$ \\
\hline TB & 1514 & $0.00 \pm 0.02$ & $-0.51 \pm 0.05$ & $0.010 \pm 0.005$ & $1.17 \pm 0.15$ & $1.80 \pm 0.48$ & $1.48 \pm 0.51$ & $-0.99 \pm 0.21$ \\
\hline $\mathrm{SCl}$ & 2053 & $<0.01$ & $-0.10 \pm 0.02$ & $0.007 \pm 0.002$ & $0.27 \pm 0.08$ & $1.04 \pm 0.45$ & $1.48 \pm 0.23$ & $-0.73 \pm 0.26$ \\
\hline $\mathrm{PE}$ & 3707 & $<0.01$ & $-0.02 \pm 0.02$ & $0.004 \pm 0.001$ & $0.28 \pm 0.07$ & $0.50 \pm 0.13$ & $0.62 \pm 0.12$ & $-0.63 \pm 0.25$ \\
\hline $\mathbf{S M}^{*}$ & 905 & - & $-1.10 \pm 0.31$ & $0.097 \pm 0.046$ & $1.47 \pm 0.31$ & $2.15 \pm 1.04$ & $2.70 \pm 1.33$ & $-0.36 \pm 0.18$ \\
\hline Cat\# & 1300 & - & - & - & - & - & - & $-2.0--2.8$ \\
\hline $\mathrm{SCl} \dagger$ & 1900 & - & $-0.11 \pm 0.04$ & - & $0.41 \pm 0.13$ & - & - & $-0.63--0.85$ \\
\hline $\mathrm{PE} \ddagger$ & 3815 & $0.003-0.28$ & $-0.01-0.64$ & $-0.005 \pm 0.005$ & - & - & - & $-1.5--2.4$ \\
\hline
\end{tabular}

*Average of BECI and Bottom Lander flux determinations (Jahnke, 1990). \#Range of values reported (Smith et al., 1983; 1987).

$\nmid$ Bottom Lander flux determinations, range for oxygen based on different model fits to $\mathrm{O}_{2}$ data (Bender et al., 1989). $\ddagger$ Range of values reported (Smith et al., 1979; 1983; Reimers and Smith, 1986).

most variability from chamber to chamber and site to site but are generally larger and out of the sediments (positive) at sites above the oxygen minimum and small but positive at the sites below $1500 \mathrm{~m}$. However, sites within the oxygen minimum zone of the $\mathrm{CC}$ transect show small fluxes both into and out of the sediments. Alkalinity efflux is larger at the shallower stations $\left(2-6 \mathrm{meq} / \mathrm{m}^{2} \mathrm{~d}\right)$, but the differential between these and deeper stations is not as great for this parameter as for oxygen or $\mathrm{TCO}_{2}$. Dissolved silica efflux is 2-7 times greater on the central California shelf than at depths below $500 \mathrm{~m}$.

Regional differences in fluxes are not dramatic (Fig. 3), although at sites below $850 \mathrm{~m}$, the borderland basins contain water with lower oxygen concentrations than off central California. The release of dissolved silica from sediments and uptake of oxygen both show a small but systematic difference between central and southern California sites. At sites below $850 \mathrm{~m}$, there is a greater flux of dissolved silica from CC area sediments $\left(1.70 \pm 0.64 \mathrm{mmol} / \mathrm{m}^{2} \mathrm{~d}\right)$ than from the Basins region $\left(0.70 \pm 0.38 \mathrm{mmol} / \mathrm{m}^{2} \mathrm{~d}\right)$. The rate of oxygen consumption is greater in the $\mathrm{CC}$ region than the basins region, although the difference is not statistically significant.

Temporal variability is difficult to gage from only two cruise periods. Three stations 

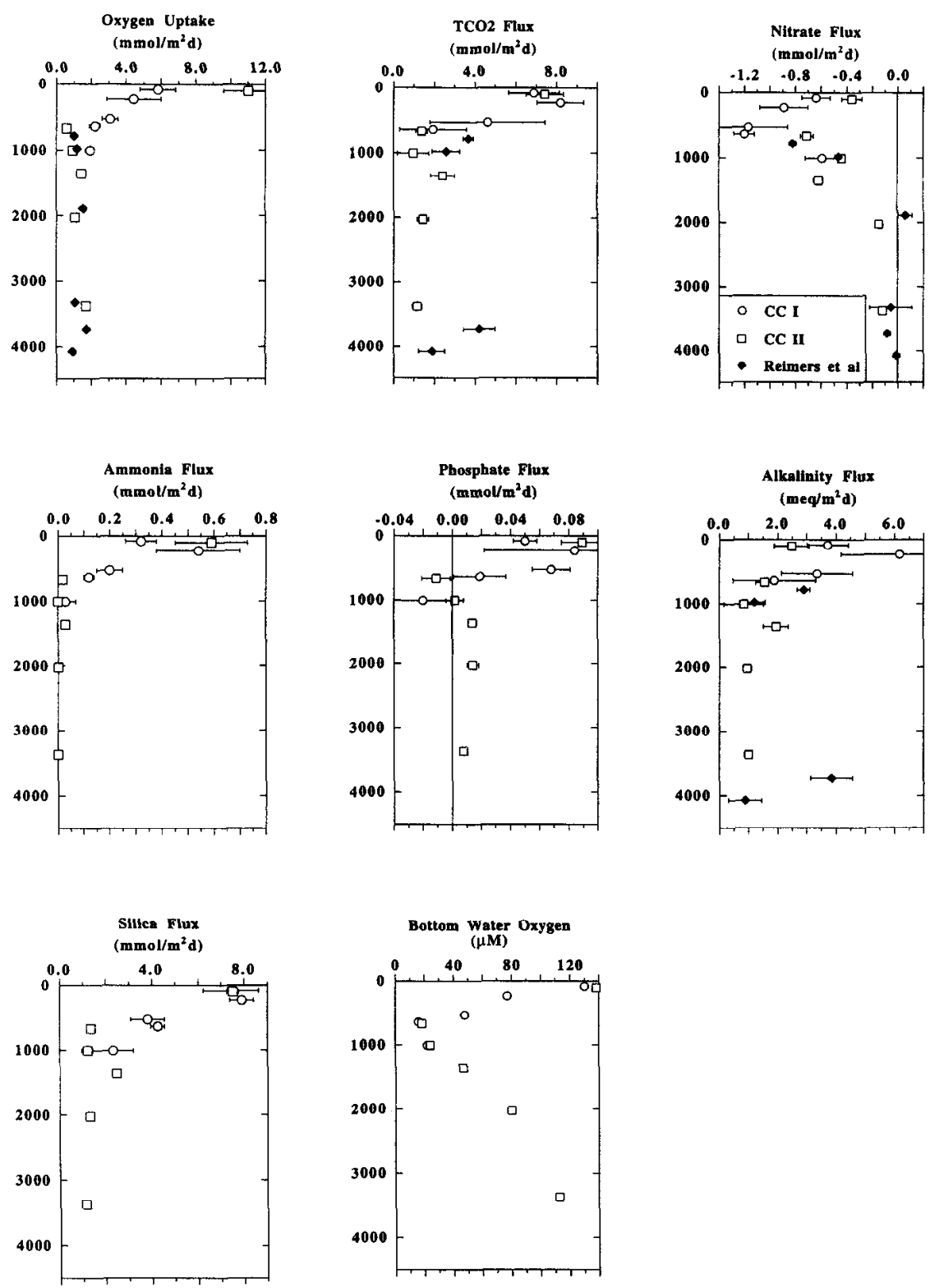

Figure 2. Benthic fluxes from the $\mathrm{CC}$ region as a function of station depth (m). Error bars denote \pm 1 s.e. of the mean (see text). Data from the previously published BECI results (Reimers et al., 1992) are also shown. The bottom-right panel shows water column profiles of oxygen concentration, measured by Winkler techniques from Niskin samples. 

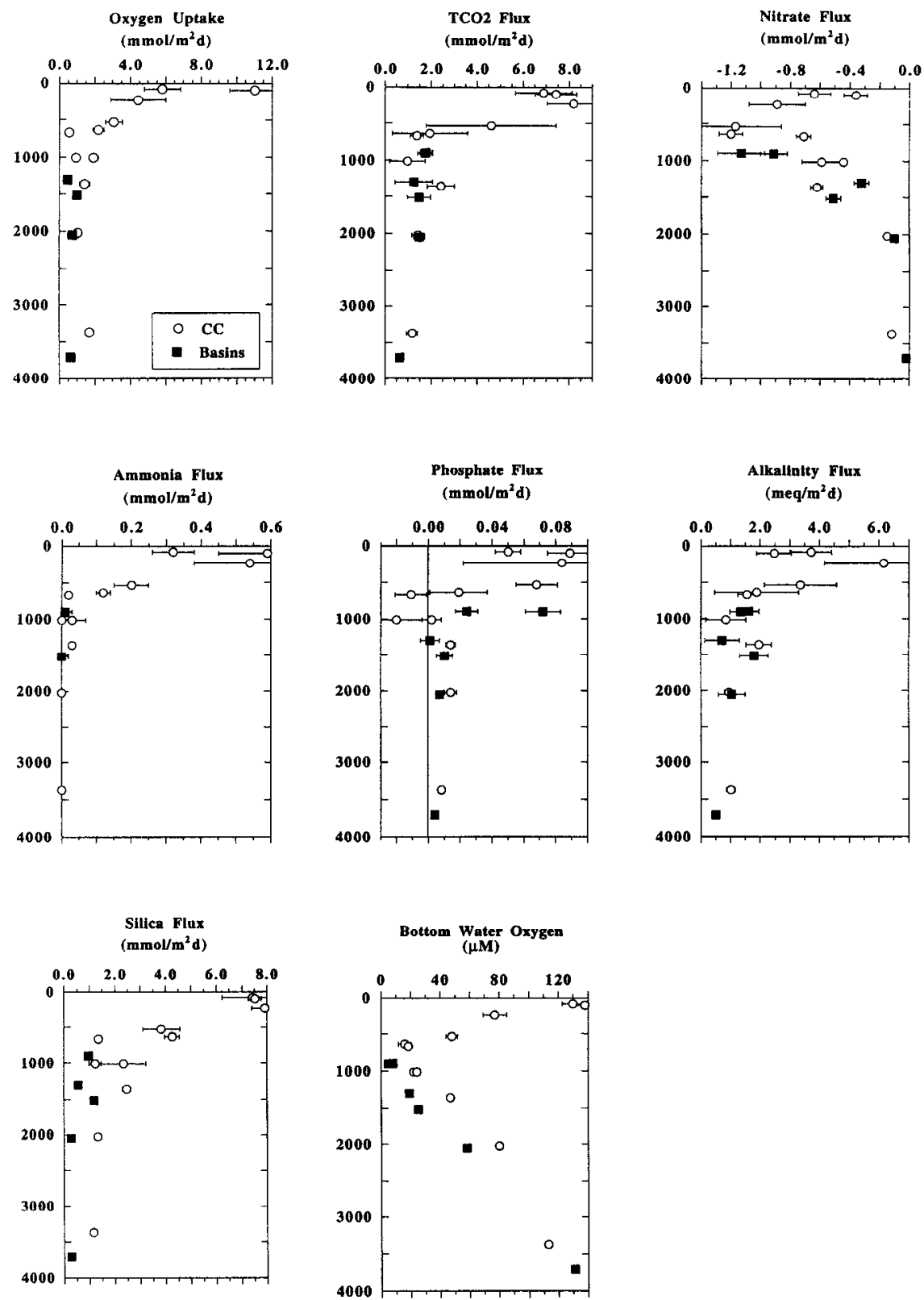

Figure 3. Benthic fluxes from the southern California basins and the $\mathrm{CC}$ region as a function of depth (m). The bottom-right panel shows water column profiles of oxygen concentration, measured by Winkler techniques from Niskin samples. 
Table 3. Rates of carbonate dissolution and carbon oxidation.

\begin{tabular}{|c|c|c|c|c|c|c|}
\hline \multicolumn{2}{|c|}{$\begin{array}{l}\text { Station } \\
\text { ID-Depth }\end{array}$} & $\begin{array}{c}\mathrm{TCO}_{2} \\
\left(\mathrm{mmol} / \mathrm{m}^{2} \mathrm{~d}\right)\end{array}$ & $\begin{array}{c}\mathrm{Alk}_{\text {corr. }} \\
\left(\mathrm{meq} / \mathrm{m}^{2} \mathrm{~d}\right)\end{array}$ & $\begin{array}{l}\text { Net Sulfate } \\
\text { Red. } \\
\left(\mathrm{mmolS} / \mathrm{m}^{2} \mathrm{~d}\right)\end{array}$ & $\begin{array}{c}\text { Net Diss. } \\
\mathrm{CaCO}_{3} \\
\left(\mathrm{mmol} / \mathrm{m}^{2} \mathrm{~d}\right)\end{array}$ & $\begin{array}{c}\mathrm{C}_{\mathrm{ox}} \\
\left(\mathrm{mmol} / \mathrm{m}^{2} \mathrm{~d}\right)\end{array}$ \\
\hline \multicolumn{7}{|l|}{$\mathrm{CC} \mathrm{I}$} \\
\hline$\overline{17}$ & 95 & $6.9 \pm 1.2$ & $2.8 \pm 0.7$ & $0.6 \pm 0.3$ & $0.8 \pm 0.5$ & $6.1 \pm 1.3$ \\
\hline 6 & 231 & $8.2 \pm 1.2$ & $4.7 \pm 2.0$ & $0.2 \pm 0.1$ & $2.2 \pm 1.0$ & $6.0 \pm 1.5$ \\
\hline 5 & 532 & $4.6 \pm 2.8$ & $2.0 \pm 1.3$ & $0.2 \pm 0.1$ & $0.8 \pm 0.6$ & $3.8 \pm 2.9$ \\
\hline 7 & 638 & $2.0 \pm 1.6$ & $0.6 \pm 1.4$ & $0.1 \pm 0.1$ & $0.2 \pm 0.7$ & $1.8 \pm 1.8$ \\
\hline \multicolumn{7}{|c|}{ CC II } \\
\hline 1 & 97 & $7.4 \pm 0.9$ & $1.5 \pm 0.6$ & $0.6 \pm 0.3$ & $0.2 \pm 0.4$ & $7.3 \pm 1.0$ \\
\hline 2 & 670 & $1.4 \pm 0.3$ & $0.8 \pm 0.3$ & $0.1 \pm 0.1$ & $0.3 \pm 0.2$ & $1.1 \pm 0.3$ \\
\hline 3 & 1010 & $1.0 \pm 0.8$ & $0.4 \pm 0.7$ & $0.1 \pm 0.1$ & $0.1 \pm 0.3$ & $0.9 \pm 0.8$ \\
\hline 6 & 1358 & $2.4 \pm 0.6$ & $1.3 \pm 0.4$ & $0.05 \pm 0.05$ & $0.6 \pm 0.2$ & $1.8 \pm 0.6$ \\
\hline 4 & 2025 & $1.4 \pm 0.3$ & $0.8 \pm 0.2$ & $0.03 \pm 0.03$ & $0.4 \pm 0.1$ & $1.1 \pm 0.3$ \\
\hline 5 & 3375 & $1.2 \pm 0.3$ & $0.9 \pm 0.1$ & $0.01 \pm 0.01$ & $0.4 \pm 0.1$ & $0.7 \pm 0.3$ \\
\hline \multicolumn{7}{|c|}{ Basins } \\
\hline$\overline{\mathrm{SP}}$ & 896 & $1.8 \pm 0.3$ & $0.5 \pm 0.4$ & $0.23 \pm 0.10$ & $0.0 \pm 0.2$ & $1.8 \pm 0.4$ \\
\hline SM & 905 & $1.7 \pm 0.3$ & $0.4 \pm 0.4$ & $0.34 \pm 0.10$ & $0.0 \pm 0.2$ & $1.7 \pm 0.4$ \\
\hline Cat & 1300 & $1.2 \pm 0.8$ & $0.4 \pm 0.6$ & $0.15 \pm 0.10$ & $0.1 \pm 0.3$ & $1.2 \pm 0.9$ \\
\hline TB & 1514 & $1.5 \pm 0.5$ & $1.3 \pm 0.5$ & $0.05 \pm 0.05$ & $0.6 \pm 0.3$ & $0.9 \pm 0.6$ \\
\hline $\mathrm{SCl}$ & 2053 & $1.5 \pm 0.2$ & $0.9 \pm 0.5$ & $0.12 \pm 0.05$ & $0.4 \pm 0.2$ & $1.1 \pm 0.3$ \\
\hline $\mathrm{PE}$ & 3707 & $0.6 \pm 0.1$ & $0.5 \pm 0.1$ & $0.03 \pm 0.03$ & $0.2 \pm 0.1$ & $0.4 \pm 0.1$ \\
\hline
\end{tabular}

$\mathrm{Alk}_{\text {corr. }}$ is determined from the measured alkalinity flux + nitrate flux - ammonium flux.

Net Sulfate Reduction is determined from sediment $S$ accumulation rate and sulfate and ammonium pore water profile models (see text).

$\mathrm{Net} \mathrm{CaCO}_{3}$ Dissolution is determined as $0.5 *$ ( $\mathrm{Alk}_{\text {corr }}-2 * \mathrm{Net} \mathrm{SO}_{4}$ reduction).

$\mathrm{C}_{\mathrm{ox}}$ is defined as the difference between $\mathrm{TCO}_{2}$ flux and $\mathrm{Net}^{\mathrm{CaCO}} \mathrm{CO}_{3}$ dissolution.

were visited during both the CC I and II cruise periods. The stations repeated were at approximately 100,640 and $1000 \mathrm{~m}$ and there is no coherence in flux trends, although at the two deeper stations, oxygen fluxes were significantly greater during CC I compared to II. However, this relationship does not hold for the $100 \mathrm{~m}$ station. The difference in oxygen fluxes during the two $\mathrm{CC}$ cruise periods is discussed further below.

b. Carbon oxidation and carbonate dissolution. The efflux of remineralized organic carbon to the overlying water $\left(\mathrm{C}_{\mathrm{ox}}\right)$ was determined from measurements of total $\mathrm{CO}_{2}$ fluxes and estimates of the portion of this flux attributable to calcium carbonate dissolution. The $\mathrm{TCO}_{2}$ flux was determined by direct chamber measurement and thus this term and its uncertainty are well defined. An upper limit for carbonate dissolution is equal to half the total alkalinity flux (alkalinity flux is expressed in equivalents). However, the total alkalinity flux includes the contribution of ammonium and nitrate fluxes, thus we define a

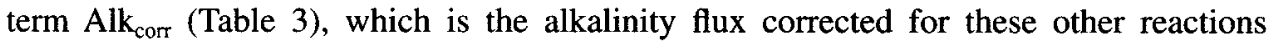


(Berelson et al., 1994; Hammond et al., 1996). The $\mathrm{Alk}_{\mathrm{cor}}$ flux is a measure of the transport of bicarbonate and carbonate ions across the sediment-water interface attributable to either $\mathrm{CaCO}_{3}$ dissolution or net sulfate reduction. If all of the $\mathrm{Alk}_{\text {corr }}$ flux is due to carbonate dissolution, the value of $\mathrm{C}_{\mathrm{ox}}$ is the difference; $\mathrm{TCO}_{2}$ flux $-0.5 *(\mathrm{Alk})_{\mathrm{corr}}$ flux. If all the $\mathrm{Alk}_{\text {corr }}$ flux is due to net sulfate reduction, $\mathrm{C}_{\mathrm{ox}}=\mathrm{TCO}_{2}$ flux. At many stations, the range between upper and lower limit estimates of $\mathrm{C}_{\mathrm{ox}}$ is quite small.

It is possible to define $\mathrm{C}_{\mathrm{ox}}$ more accurately than by an upper and lower limit because values of net sulfate reduction were estimated for all of the stations. At the CC stations, solid $\mathrm{S}$ was measured in sediment cores from several intervals and net sulfate reduction was assumed equal to the burial flux of sulfur (Leslie $e t$ al., 1990). The sediment burial rate term used in this calculation is an average from reported values of Reimers et al. (1992), unpublished values supplied by J. Gardner (USGS, pers. comm.), and our unpublished $\mathrm{Pb}-210$ data for a shelf station (Table 4). The range in sediment accumulation rate measurements for a given depth zone is large, hence the uncertainty in our estimate of net sulfate reduction is large.

At several southern California stations, there are data in addition to sedimentary sulfur measurements that help establish net sulfate reduction rates. The mean sulfate reduction rates presented in Table 3 incorporate previously published estimates for SM (Jahnke, 1990), SCl (Bender et al., 1989), SP and Cat Basins (Leslie et al., 1990). Additionally, at these stations and PE and TB, pore water profiles of ammonium and sulfate were collected from multi-cores which were sectioned and centrifuged. These profiles were fit, as described by Leslie et al. (1990), and the resulting estimates of net sulfate reduction were also incorporated into the mean values presented in Table 3.

It is clear from the values determined by this method that net sulfate reduction can account for a wide range, $2-100 \%$, of the $\mathrm{Alk}_{\text {corr }}$ flux. It is very encouraging, from a stoichiometric viewpoint, that the sediment and pore water estimates of net sulfate reduction do not predict alkalinity fluxes greater than measured with the chambers. In general, at the sites located within the oxygen minimum zone, most or all of the observed alkalinity flux can be accounted for by the flux of ammonium, nitrate uptake, and net

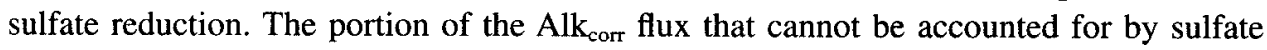
reduction is attributed to calcium carbonate dissolution. Although the uncertainties which carry through this calculation are usually quite large, the pattern of $\mathrm{CaCO}_{3}$ dissolution on the sea floor of both regions is similar (Fig. 4). Dissolution rates are lowest within the oxygen minimum zone, but dissolution is occurring both above and below this depth range.

\section{Discussion}

a. Comparison of in situ benthic chambers. The USC Lander, FVGR (Smith et al., 1979), Bottom Lander (Bender et al., 1989) and BECI (Jahnke and Christiansen, 1989) are devices of quite different design but similar function (Berelson et al., 1987b; Tengberg et al., 1995). During cruises in July ' 87 , November ' 87 , July ' 88 and Junc ' 89 BECI was deployed in the region off Point Sur and Pt. Peidras Blancas and fluxes of oxygen, $\mathrm{TCO}_{2}$, 
Table 4. Carbon Burial Efficiency $=\mathrm{C}_{\text {org }}$ burial rate $\div\left[\mathrm{C}_{\text {org }}\right.$ burial rate $\left.+\mathrm{C}_{\mathrm{ox}}\right]$.

\begin{tabular}{|c|c|c|c|c|c|c|}
\hline Station & $\begin{array}{l}\text { Depth } \\
\text { (m) }\end{array}$ & $\begin{array}{c}\mathrm{BW} \mathrm{O}_{2} \\
(\mu \mathrm{M})\end{array}$ & $\begin{array}{l}\text { Sed. Mass } \\
\text { Accum. Rate } \\
\left(\mathrm{mg} / \mathrm{cm}^{2} \mathrm{yr}\right)\end{array}$ & $\begin{array}{c}\mathrm{C}_{\text {org }} \text { Burial } \\
\text { Rate } \\
\left(\mathrm{mmol} / \mathrm{m}^{2} \mathrm{~d}\right)\end{array}$ & $\begin{array}{c}\mathrm{C}_{\mathrm{ox}} \\
\left(\mathrm{mmol} / \mathrm{m}^{2} \mathrm{~d}\right)\end{array}$ & $\begin{array}{c}\mathrm{C}_{\text {org }} \text { Burial } \\
\text { Efficiency } \\
(\%)\end{array}$ \\
\hline \multicolumn{7}{|c|}{ Central Calif.* } \\
\hline $\mathrm{J}$ & 781 & 12 & 7.4 & 0.49 & $2.0,1.1$ & 20,31 \\
\hline $\mathrm{K}$ & 1000 & 20 & 3.6 & 0.38 & $1.8,1.4$ & 17,21 \\
\hline D & 1443 & 38 & 1.1 & 0.04 & $2.0,1.8$ & 2,2 \\
\hline $\mathrm{L}$ & 1894 & 74 & 2.0 & 0.05 & $1.5,1.1$ & 3,4 \\
\hline \multirow[t]{2}{*}{$\mathrm{G}$} & 3344 & 123 & 2.6 & 0.18 & $2.0,0.7$ & 8,20 \\
\hline & 3319 & 123 & 11.1 & 0.66 & $2.0,0.7$ & 25,49 \\
\hline $\mathrm{H}$ & 3592 & 128 & 2.7 & 0.08 & $1.8,0.7$ & 4,10 \\
\hline \multicolumn{7}{|c|}{ Southern Calif.\# } \\
\hline $\mathrm{SP}$ & 890 & 8 & $13^{1}$ & $1.5^{5,6}$ & 1.8 & 45 \\
\hline SP & 890 & 8 & $29^{1}$ & $2.6^{5,6}$ & 1.8 & 59 \\
\hline SM & 910 & 5 & $16^{1}$ & $1.8^{5,7}$ & 1.7 & 51 \\
\hline Cat & 1300 & 19 & $14^{2,3}$ & $1.4^{5,6}$ & 1.2 & 54 \\
\hline SN & 1800 & 25 & $14^{2,4}$ & $1.9^{8,9}$ & 1.3 & 59 \\
\hline TB & 1514 & 25 & $12^{2}$ & $1.4^{2}$ & 0.9 & 61 \\
\hline $\mathrm{SCl}$ & 2024 & 58 & $15^{2}$ & $0.9^{5,9}$ & 1.1 & 45 \\
\hline $\mathrm{PE}$ & 3707 & 131 & $3^{2}$ & $0.08^{9}$ & 0.4 & 17 \\
\hline
\end{tabular}

*Central California stations and accumulation rate data from Reimers et al. (1992). The first $\mathrm{C}_{\mathrm{ox}}$ value is from Reimers et al. (1992), the second value is from this paper. Where station depths did not correspond, the CC station closest in depth to the Reimers et al. (1992) station is used. Two values of $\mathrm{C}_{\text {org }}$ burial efficiency are also given.

\#Southern California sediment accumulation rate data are compilations from many sources: ${ }^{1} \mathrm{Huh}$ et al. (1990), ${ }^{2}$ Schwalbach and Gorsline (1985), ${ }^{3}$ Brandsma et al. $(1989),{ }^{4}$ Bruland et al. (1981). $C_{\text {org }}$ burial rates derived from sediment accumulation rates and $\% \mathrm{C}_{\mathrm{org}}$ from various sources: ${ }^{5} \mathrm{Jahnke}$ (1990), ${ }^{6}$ Leslie et al. (1990), ${ }^{7}$ Gorsline (1992), ${ }^{8}$ Berelson et al. (1987a), ${ }^{9}$ Shaw et al. (1990).

The $\mathrm{C}_{\mathrm{ox}}$ values for Southern California are from this paper. Two sediment accumulation and $\mathrm{C}_{\text {org }}$ burial rates are given for San Pedro Basin based on the two rates given by Huh et al. (1990). The first value represents the sedimentation rate between 1900-1980, the second represents the sedimentation rate between 1800-1900. The San Nicolas Basin $C_{o x}$ data from Berelson et al. (1987a).

nitrate and alkalinity were reported (Jahnke et al., 1990; Reimers et al., 1992). Not every station occupied by BECI is covered by one of our deployments, but for similar depths, the fluxes of common analytes agree to within \pm 2 s.e. (Fig. 2). There is no systematic difference between the flux values determined during the $\mathrm{CC}$ cruises and from the BECI data.

BECI and the Bottom Lander have also been deployed in Santa Monica Basin (Jahnke, 1990). Fluxes of nitrate, phosphate, silica, alkalinity and $\mathrm{TCO}_{2}$ determined with these devices agree with the fluxes reported in this paper to \pm 1 s.e. (Table 2). Benthic fluxes measured in San Clemente Basin with the Bottom Lander (Bender et al., 1989) also agree with the USC Lander fluxes. However, USC Lander oxygen flux determinations are consistently lower than the values obtained with the FVGR (Smith et al., 1987, 1979) for 

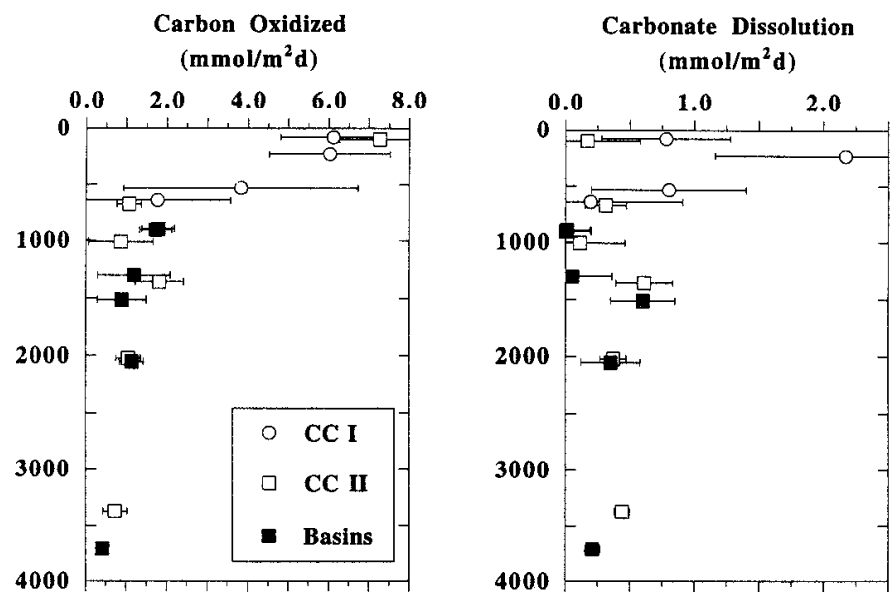

Figure 4. The calculated fluxes of organic carbon oxidized $\left(\mathrm{C}_{\mathrm{ox}}\right)$ and carbonate dissolved, as a function of depth $(\mathrm{m})$. Error bars represent uncertainties carried through the calculation of each of these derived parameters (see text).

Catalina Basin and the Patton Escarpment site. Although our 1994 oxygen flux values for Catalina Basin are about $60 \%$ of the mean flux determined from previous USC Lander deployments (Berelson, unpub. data), the previous data agree well with flux estimates derived from in situ micro-electrode oxygen profiles (Reimers et al., 1986; Archer and Devol, 1992) which establish an average oxygen uptake rate of about $0.9 \mathrm{mmol} / \mathrm{m}^{2} \mathrm{~d}$. With the exception of the flux values presented by Smith et al. (1979), there is reasonable agreement between the USC Lander and the FVGR nutrient flux estimates at the Patton Escarpment site (Table 2), although the difference in oxygen flux estimates is about a factor of $2-4$.

The general agreement between fluxes measured with different benthic chambers demonstrates the constancy of benthic reactions and pore water-overlying water exchange within a factor of 2-3 over 3-10 year time scales. Some of the difference in flux values determined by different devices may be attributed to heterogeneity on the sea floor. Most of the USC Lander fluxes represent averages of 2 or 3 chambers, each covering $0.07 \mathrm{~m}^{2}$ but spaced over roughly $1 \mathrm{~m}^{2}$ of sea floor. The variability in fluxes within a $1 \mathrm{~m}^{2}$ plot of sea floor is illustrated by scanning the data in Table 1. Individual chamber fluxes at most stations agree within the uncertainty of each measurement, but a factor of 2 or 3 difference in flux between two adjacent chambers does occur occasionally. The generally good agreement between chamber fluxes measured with all devices points to a general consistency in benthic fluxes throughout the regions studied, both in time and space. Further, the results indicate that there is compatibility in the use and treatment of benthic chamber data between several chamber operating groups.

b. Carbon oxidation as a function of depth. The rate at which labile or highly reactive biogenic matter is delivered to the sea floor will be a major factor controlling benthic 

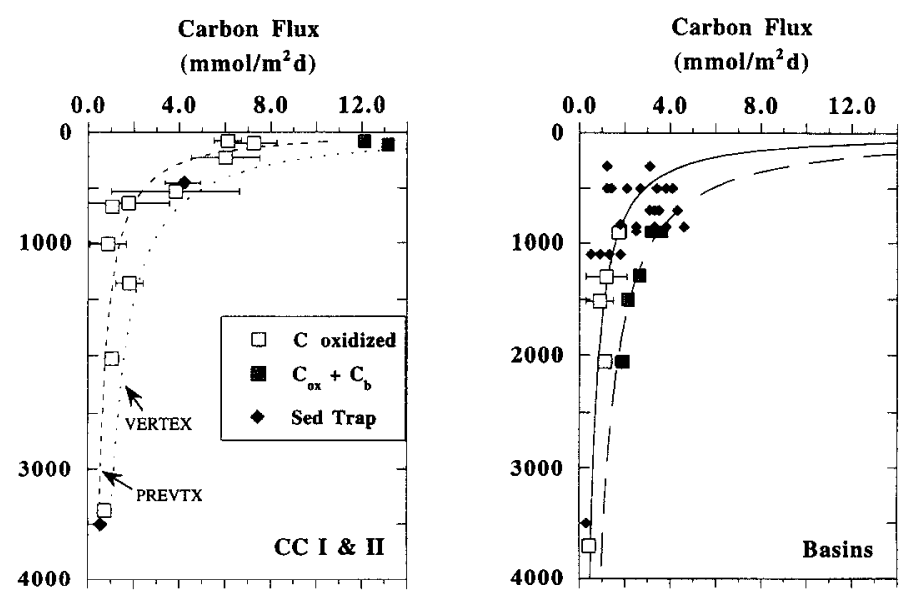

Figure 5. Organic carbon fluxes as a function of depth $(m)$. Open squares are $C_{0 x}$ data, shaded squares are values of $\mathrm{C}_{\mathrm{ox}}+\mathrm{C}_{\text {org }}$ accumulation, solid diamonds represent sediment trap $\mathrm{C}_{\text {org }}$ rain data. (a) In the central California region, the shallow trap is the average flux for a sediment trap located in Monterey Canyon (Pilskaln et al., 1996), the deep trap is the average rain rate presented by Smith et al. (1994). The two curves indicate fits to data presented in Martin et al. (1987). (b) Data from southern California. Sediment trap $\mathrm{C}_{\text {org }}$ rain data at sites $<1000 \mathrm{~m}$ are cited in Thunell et al. (1994), Nelson et al. (1987) and Eganhouse and Venkatesan (1993) and references therein. All of these trap data are located in SP and SM Basins. Trap data below $1000 \mathrm{~m}$ from Smith (1987) and derived from traps located in Catalina and the Patton Escarpment. Two fits of the Martin function to the Basins data are presented, a solid line is fit to $\mathrm{C}_{\mathrm{ox}}$ values, and the dashed line is fit through the sum of $\mathrm{C}_{\mathrm{ox}}+\mathrm{C}_{\mathrm{b}}$.

recycling rates. If the delivery of reactive carbon to the sediment is assumed to originate from production in the surface ocean, there may be a predictable pattern of sea floor diagenesis as a function of depth corresponding to a loss of the most reactive components with settling time. Martin et al. (1987) described the flux of particulate organic carbon to a sediment trap $(F)$ as a function of depth by fitting cmpirical data from many different environments to the power law, $F=F_{100}(z / 100)^{-b}$, where $F_{100}$ is the flux of carbon below the $100 \mathrm{~m}$ depth horizon and $b$ is a constant. We have compared benthic $\mathrm{C}_{\mathrm{ox}}$ data for the $\mathrm{CC}$ I and II and Basins regions (Fig. 5) to the Martin function to test the hypothesis that the pattern of carbon rain through the water column will be reflected in the pattern of carbon recycling within the sediments (Jahnke et al., 1990; Reimers et al., 1992, Rowe et al., 1994).

Sediment trap data from the CC region (Fig. 1) have been modeled by Martin et al. (1987) and the pattern of carbon rain vs. depth, defined by these measurements, envelope the benthic $\mathrm{C}_{\mathrm{ox}}$ data (Fig. 5a). However, the trap data predict more carbon arriving at $100 \mathrm{~m}$ than can be accounted for by sea floor oxidation. This is to be expected if a significant portion of the carbon arriving on the central California shelf is buried in shelf sediments or transported outside of the study area. Estimates of organic $C$ burial $\left(C_{b}\right)$ in Monterey Bay shelf sediments, based on estimates of the sediment accumulation rate from measurements of $\mathrm{Pb}-210$ in two cores (D. Colodner, LDEO, pers. comm. and USC, unpub. data) 
combined with measurements of weight $\%$ organic carbon in shelf sediments $(1 \mathrm{wt} . \%$, MLML unpub. data), put an upper limit for carbon burial at about $6 \mathrm{mmol} / \mathrm{m}^{2} \mathrm{~d}$, approximately equal to the rate of carbon oxidation. Thus, the addition of $C_{o x}+C_{b}$ predicts a carbon rain rate consistent with the sediment trap models. A continuous time series of trap measurements made between 1989 and 1992 from a site near Montercy Canyon (Fig. 1) define an average organic carbon rain rate at $450 \mathrm{~m}$ (Fig. 5a). The mean organic carbon rain rate falls between the values derived by Martin et al. (1987). Smith et al. (1994) also report organic carbon rain rates from a site near the CC study region (Fig. 1). The results of long (606 day) trap deployments are comparable with shorter (60-70 day) deployments and indicate an average rain of $0.55 \pm 0.21 \mathrm{mmolC} / \mathrm{m}^{2} \mathrm{~d}$. This value is consistent with the $\mathrm{C}_{\mathrm{ox}}$ data presented here and with the predicted rain rates based on the floating trap deployments of Martin et al. (1987). Given the expected differences in measurements over different spatial and temporal scales, benthic $\mathrm{C}_{\mathrm{ox}}$ generally follows the power law relationship predicted of organic carbon $\left(\mathrm{C}_{\mathrm{org}}\right)$ rain as a function of depth.

Missing from this discussion is consideration of the $\mathrm{C}_{\mathrm{org}}$ buried within the sediments along this transect. However, at sites along the CC transect between 700-3300 m, Reimers et al. (1992) found that $>74 \%$ of the organic carbon delivered to sediments is oxidized. Hence, with the exception of the shelf area, $C_{b}$ is not an important component of the carbon cycling within this region. The good fit of the Martin et al. (1987) trap data and benthic $\mathrm{C}_{\mathrm{ox}}$ data indicate that the pattern of organic carbon degradation throughout the water column is maintained when carbon arrives at the sea floor. This applies to stations located between $200 \mathrm{~m}$ and $3300 \mathrm{~m}$, through the oxygen minimum zone and through an area $>25,000 \mathrm{~km}^{2}$.

Jahnke et al. (1990) and Reimers et al. (1992) found that there was more carbon oxidized between $3300-4500 \mathrm{~m}$ than could be supported by fits to either Martin function (or other similar functions) and hypothesized that delivery of organic matter from upslope must be the source of the carbon oxidized at depth. Our results do not extend to this depth region of the excess $\mathrm{C}_{\mathrm{ox}}$, but our transect measurements may constrain sources of the excess organic carbon. The excess of oxidation over supply is $1-2 \mathrm{mmol} / \mathrm{m}^{2} \mathrm{~d}$ for the depth range $3300-4500 \mathrm{~m}$ (Reimers et al., 1992). Hence, a similar deficiency where $\mathrm{C}_{\mathrm{ox}}<\mathrm{C}_{\text {org }}$ rain should be found upslope of the excess. If the VERTEX profile of $\mathrm{C}_{\text {org }}$ rain characterizes the region, there may be sufficient deficiency upslope, particularly between $500-1000 \mathrm{~m}$. However, if the PREVTX profile is more characteristic of the region, there does not appear to be a region of the slope that is deficient in $\mathrm{C}_{\mathrm{ox}}$ relative to $\mathrm{C}_{\mathrm{org}}$ rain (Fig. 5a). If we assume that the excess carbon is derived from the shelf and that the area of the shelf is $10 \%$ the area covered by this budget excess, it would require that supply of carbon by vertical rain exceed oxidation plus burial by $10-20 \mathrm{mmol} / \mathrm{m}^{2} \mathrm{~d}$. The shelf value of $\mathrm{C}_{\mathrm{ox}}+\mathrm{C}_{\mathrm{b}}$ is $12-14 \mathrm{mmol} / \mathrm{m}^{2} \mathrm{~d} ; F_{100}$ rain rate estimates vary between $10-20 \mathrm{mmol} / \mathrm{m}^{2} \mathrm{~d}$ (Martin et al., 1987). Hence, it is possible that the source of deep $C_{o x}$ is derived from productivity and rain to the shelf.

There are obvious difficulties in taking the Martin 1-dimensional model approach and applying it to data collected over different depth and spatial scales. Periodic, high regional 
productivity may be associated with high currents capable of sweeping organic matter downslope or into submarine canyons (Reimers et al., 1992). The Martin model assumes a constant surface ocean production rate, yet coastal regions such as those studied here are likely to experience considerable variability in spatial and temporal patterns (Chavez, pers. comm.). Nonetheless, although the 'snapshot' picture of benthic carbon cycling that we examined during two time periods may not be representative of the time periods studied by others, the $C_{o x}$ data throughout the depth range $100 \mathrm{~m}-3300 \mathrm{~m}$, is consistent with the Martin power law function of organic carbon rain through the water column and consistent with two long time average $\mathrm{C}_{\text {org }}$ rain rate measurements within the region.

Within the southern Califomia basins region, $C_{b}$ measurements indicate that a large fraction of the organic carbon arriving at these sites gets buried (Table 4). Although the sum of $C_{o x}+C_{b}$ should predict the pattern of carbon rain to the sea floor, there are problems in treating borderland basin carbon budgets with a one dimensional model as evidenced when trying to balance trap, $\mathrm{C}_{\mathrm{ox}}$ and burial data. $\mathrm{C}_{\mathrm{ox}}+\mathrm{C}_{\mathrm{b}}$ data are well fit by the Martin function when $\mathrm{b}$ and $F_{100}$ are free variables (Fig. $5 \mathrm{~b}$ ). This function is consistent with sediment trap data from the nearshore basins for traps located between $700-900 \mathrm{~m}$, but predicts a much larger rain of organic carbon at a depth of $300-500 \mathrm{~m}$ and $>1000 \mathrm{~m}$ than has been observed in sediment traps deployed within the region. A fit of the $\mathrm{C}_{\mathrm{ox}}$ data alone is more consistent with all of the trap data.

The $F_{100}$ values for curves fit to the $\mathrm{C}_{\mathrm{ox}}$ and the $\mathrm{C}_{\mathrm{ox}}+\mathrm{C}_{\mathrm{b}}$ data predict export rates of organic carbon of 12 and $19 \mathrm{mmol} / \mathrm{m}^{2} \mathrm{~d}$, respectively. This is consistent with the range of values measured $\left(10 \mathrm{mmol} / \mathrm{m}^{2} \mathrm{~d}\right.$, sediment trap data, Landry et al., 1992) and predicted $\left(20 \mathrm{mmol} / \mathrm{m}^{2} \mathrm{~d}\right.$, based on primary productivity measurements and estimates of export ratios, Eppley, 1992), and hence offers no constraint in defining which curve-fit is more appropriate for this region. However, if $\mathrm{C}_{\mathrm{ox}}+\mathrm{C}_{\mathrm{b}}$ are used to define the pattern of carbon delivery to this margin, the predicted carbon rain rate to a site off the Patton Escarpment would be 2-3 times the measured oxidation rate, suggesting a burial rate of $>1 \mathrm{mmol} / \mathrm{m}^{2} \mathrm{~d}$. Estimates of $\mathrm{C}_{\mathrm{b}}$ for this region range between 0.03 and $0.07 \mathrm{mmol} / \mathrm{m}^{2} \mathrm{~d}$ (Reimers and Smith, 1986; Shaw et al., 1990). Our $C_{o x}$ data for the Patton Escarpment $(0.4 \pm$ $0.1 \mathrm{mmol} / \mathrm{m}^{2} \mathrm{~d}$ ) are consistent with sediment trap results from this region which, albeit short deployments of $<7$ days, record the organic carbon rain rate at $0.3 \pm 0.1 \mathrm{mmol} / \mathrm{m}^{2}$ (Smith, 1987). It is clear that the southern California region cannot be characterized by a simple function describing $\mathrm{C}_{\text {org }}$ rain which also describes the $\mathrm{C}_{\mathrm{ox}}+\mathrm{C}_{\mathrm{b}}$ and sediment trap data.

The compilation of published trap data indicate an increase in the flux of organic carbon as a function of depth to sediment traps deployed within the nearshore basins (Fig. 5b). Huh et al. $(1990,1992)$ used radioisotopic measurements of trap and sediment material to conclude that the central floor of Santa Monica and San Pedro Basins receive sediments that have been transported laterally as suspended particles. This, and other reports of sediment re-suspension on the slopes of the borderland basins (Gorsline, 1992) indicate that sediment accumulation in these basins is not controlled only by the vertical rain 
process. Horizontal focusing of sediment and organic carbon de-couples the carbon budget for the basins from the supply of organic carbon from the upper ocean. Smith et al. (1994) found this was true for an abyssal site off central California in $4100 \mathrm{~m}$ water depth. Further support of this phenomena comes from measurements of ${ }^{14} \mathrm{C}$ in sinking and suspended organic carbon in the nearshore borderland basins which show increases in the age of sediment trap and suspended $\mathrm{C}_{\text {org }}$ with depth (Williams et al., 1992).

The profile of $\mathrm{C}_{\mathrm{ox}}$ with depth within the borderland region is consistent with sediment trap data from most of the water column, estimates of $\mathrm{C}_{\text {org }}$ export from the surface ocean, and a Martin-like power law of carbon degradation. Although this flux is sufficient to support the rate of carbon oxidation on the sea floor within this region, productivity and vertical rain does not support the total flux of organic carbon arriving on the central basin floor over 100-1000 year time scales. Within the basins, horizontal inputs of organic carbon contribute to the overall carbon balance.

Work by Burdige et al. $(1992 ; 1996)$ indicates that the diffusive DOC flux from sediments within the borderland basins is not likely to contribute more than $20 \%$ of the total DIC flux, although this value is not well constrained. However, water column DIC budgets (Berelson et al., 1987a) and ${ }^{14} \mathrm{C}$ budgets (Bauer et al., 1995) suggest that this is a reasonable limit. Work from other marine environments put the contribution of DOC at $<20 \%$ of the DIC efflux (Martin et al., 1991). Hence, in this paper we do not add the flux of DOC from margin sediments as part of the sediment carbon budget.

c. Carbon preservation. Organic carbon remineralization rates are similar for both California margin regions between 800-3500 m depth. However, organic carbon arriving on the sea floor off southern California is more efficiently buried than carbon deposited off central California (Table 4). Although the uncertainty in burial efficiency values is large because of the different temporal scales of $\mathrm{C}_{\mathrm{ox}}$ and $\mathrm{C}_{\mathrm{b}}$ measurements, the difference between burial efficiencies in central and southern Californian sites is significant. This difference is not related to sediment depth or bottom water oxygen content. The obvious difference between these regions is the higher sediment accumulation rates for the basins relative to the central California slope.

Various hypotheses have been proposed to explain carbon preservation in marine sediments. The proximity of the nearshore basins to terrestrial and sewage derived organic matter does leave an impact on the carbon preserved in these sediments, although the contribution of terrestrial and anthropogenic sources is not well resolved (Ventkatessen and Kaplan, 1992; Williams et al., 1992). However, this source cannot explain the high carbon burial efficiencies observed in the offshore basins, where terrestrial carbon inputs are minimal (Jahnke, 1990; Jackson et al., 1989). Mayer (1994a) has shown that there is more organic carbon preserved in central California, oxygen minimum zone sediments and Catalina Basin sediments than can be accounted for by the surface area model (Mayer, 1994b). Hence models associating $C_{\text {org }}$ concentration and mineral grain surface area (Mayer, 1994b, Keil et al., 1994) cannot explain the carbon preservation pattern in either 
region. Results from Aller (1994) indicate that cycling between oxic and anoxic conditions may promote carbon oxidation above that level achieved by maintaining constant conditions. Temporal variability in bottom water hydrographic conditions are not well documented for the central California region but basin bottom waters undergo fluctuations in oxygen concentration as a result of periodic flushing (Berelson, 1991; Hickey, 1992), yet these are sites of enhanced carbon preservation, not oxidation. Another parameter to consider is whether the sediments underlying low oxygen bottom waters off central California undergo more bioturbative mixing than the sediments off southern California. This measure would test the hypotheses that the activities of sediment-mixing macrofauna promote $\mathrm{C}_{\mathrm{ox}}$ of otherwise refractory $\mathrm{C}_{\text {org }}$ (Lee, 1992; Canfield, 1994). However, as Jahnke (1990) points out, the southern California basin sediments experience a wide range in the degree of bioturbative mixing, yet do not show a correlation between this parameter and carbon preservation. Sulfate reduction accounts for $25-40 \%$ of the organic carbon oxidized in SP, SM and Cat Basins (Table 3) whereas this oxidation pathway accounts for only $6-22 \%$ of the carbon oxidized within sediments underlying the oxygen minimum zone off central California. However, sulfate reduction accounts for only 10-20\% of the carbon oxidized in TB and SCl Basins, yet carbon preservation efficiency is high, suggesting that oxidation pathway is not fundamental to carbon preservation.

In the previous section we argued that the rain of organic carbon from the upper water column in southern California was sufficient to supply $\mathrm{C}_{\mathrm{ox}}$ but not $\mathrm{C}_{\mathrm{ox}}+\mathrm{C}_{\mathrm{b}}$. One hypothesis to explain the higher burial efficiency in the basins is that a more refractory organic carbon is delivered to the deep basin floor by lateral transport off the basin slopes. The Middle Atlantic Bight is a region where both labile and refractory organic carbon are transported downslope (Biscaye et al., 1994; Anderson et al., 1994). Results from Anderson et al. (1994) suggest that the refractory $C_{\text {org }}$ is much older than the labile $C_{\text {org. }}$. Measurements of ${ }^{14} \mathrm{C}$ from Santa Monica Basin sediments (Williams et al., 1992; Bauer et al., 1995) show that two pools of sedimentary organic carbon exist, the younger pool undergoing diagenetic reaction in the upper $\mathrm{cm}$ of the sediments and an older fraction being buried.

If transport of organic carbon downslope is an important factor contributing to its preservation in the southern California region, it remains curious that down-canyon transport in the central California region does not have the same effect (Reimers et al., 1992). The depth from which the organic carbon is derived may be an important parameter distinguishing transport and oxidation in central California from transport and burial in southern California. The steep slopes and confining walls of the Southern California basins may play a major role in enhanced carbon preservation by focusing and funneling sediment and organic matter, derived from the slopes, to the basin floor. If a large proportion of this carbon is older and less reactive, it could explain the enhanced burial efficiency in southern California basins.

d. Oxygen fluxes as a function of bottom water oxygen. The abundance of oxygen dissolved in bottom water limits the distribution and abundance of macrofauna (Savrda $e t$ 
al., 1984). In addition, bottom water oxygen concentration may affect the fluxes of oxygen and other nutrients (McManus et al., in prep.; Archer and Devol, 1992; Rissgaard-Peterson et al., 1994). The relationship between bottom water oxygen concentration and oxygen uptake rate was examined as a function of location and sampling period.

Oxygen uptake and bottom water concentration may be related by solving the diagenetic equation:

$$
d C / d t=\emptyset D_{s}\left(d^{2} C / d z^{2}\right)-R=0
$$

where $C$ is oxygen concentration in pore waters, $\varnothing$ is the porosity of the surficial sediments, $D_{s}$ is oxygen diffusivity in sediments and $R$ is a 0 -order reaction rate in units of mmoles oxygen consumed per volume of sediment per unit time. Ficks first law was applied to the solution to Eq. (1) to relate the flux of oxygen into the sediments $\left(J_{\mathrm{O} 2}\right)$ and $R$ :

$$
J_{\mathrm{O} 2}=-\left(2 \varnothing D_{s} C_{0} R\right)^{1 / 2}
$$

where $C_{0}$ is the oxygen concentration at the sediment-water interface. $D_{s}$ is assumed to be proportional to $\emptyset^{2} D_{0}$ (Ullman and Aller, 1982) where $D_{0}$ is the molecular diffusivity of oxygen through sea water. The value of $C_{0}$ was established by assuming the diffusive boundary layer thickness in all the chambers was $400 \mu \mathrm{m}$, based on the stirring rate setting of 5 RPM (Berelson et al., 1990).

The formulation of Eq. (1) may not represent the actual kinetics of oxygen uptake in sediments because others have shown the reactivity of organic carbon decreases as a function of depth in the sediments (Westrich and Berner, 1984; Middleburg, 1989; Jahnke, 1990; Burdige et al., 1991; Archer and Devol, 1992; Hales et al., 1994; Hammond et al., 1996). Yet, the solution to Eq. (1) will provide a value for $R$ that is a measure of the reactivity of the sediment to oxygen uptake, and this formulation has been shown to accurately describe continental margin environments (Cai and Sayles, 1996).

Archer and Devol (1992) have shown that oxygen uptake within continental shelf sediments may be highly impacted by the activities of bio-irrigators. Their data also indicate that the irrigation effect is strongly attenuated at depths below $150 \mathrm{~m}$, hence we did not apply these equations to the data from the shelf sites (CCI-17 or CCII-1). For stations deeper than $150 \mathrm{~m}$, a comparison of $\mathrm{R}$ values from the three cruise periods (Table 5) demonstrates that oxygen consumption reactivity was 5-30 times greater from sites within the CC I transect compared to the CC II or Basins region.

Two sites from the same depths, studied during both central California margin cruises, exhibited greater oxygen uptake rates during $\mathrm{CC}$ I time. Bottom water oxygen concentration was essentially the same during these cruise periods (Fig. 2). The higher oxygen uptake rates during CC I could not be attributed to increased bio-irrigation activity as radon fluxes were equivalent at common sites during the two cruise periods (USC unpublished data). Assuming oxygen uptake is controlled primarily by reaction with organic carbon, the reactivity term can be broken into 3 components, $R=\gamma j_{\text {bulk }}\left[\mathrm{C}_{\text {org }}\right]$, where $\gamma$ represents the $\mathrm{O}_{2}: \mathrm{C}_{\mathrm{ox}}$ stoichiometric ratio, $j_{\text {bulk }}$ is the rate constant of carbon oxidation and $\left[\mathrm{C}_{\mathrm{org}}\right]$ is the 
Table 5. Oxygen reactivity and depth of penetration. Penetration depths are model calculations except micro-electrode data of Reimers et al. (1992).

\begin{tabular}{|c|c|c|c|c|}
\hline $\begin{array}{l}\text { Station } \\
\text { (Depth) }\end{array}$ & $\begin{array}{c}\mathrm{O}_{2} \text { Flux } \\
\left(\mathrm{mmol} / \mathrm{m}^{2} \mathrm{~d}\right)\end{array}$ & $\begin{array}{c}\mathrm{BW} \mathrm{O_{2 }} \\
(\mu \mathrm{M})\end{array}$ & $\begin{array}{c}R \\
\left(\mathrm{mmol} / \mathrm{m}^{3} \mathrm{~d}\right)\end{array}$ & $\begin{array}{l}\text { Depth of } \mathrm{O}_{2} \\
\text { Penetration } \\
\quad(\mathrm{cm})\end{array}$ \\
\hline \multicolumn{5}{|l|}{$\mathrm{CC} \mathrm{I}$} \\
\hline$\overline{\mathrm{T} 1-6}(231)$ & 4.44 & 77 & 1656 & 0.27 \\
\hline $\mathrm{T} 1-5(532)$ & 3.08 & 48 & 1416 & 0.22 \\
\hline $\mathrm{T} 1-7(638)$ & 2.22 & 16 & 3105 & 0.07 \\
\hline T1-12 (1010) & 1.94 & 22 & 1294 & 0.16 \\
\hline \multicolumn{5}{|l|}{ CC II } \\
\hline $\mathrm{T} 2-2(670)$ & 0.57 & 18 & 112 & 0.51 \\
\hline $\mathrm{T} 2-3(1010)$ & 0.94 & 24 & 239 & 0.39 \\
\hline T2-6 (1358) & 1.43 & 47 & 297 & 0.48 \\
\hline $\mathrm{T} 2-4(2025)$ & 1.05 & 80 & 89 & 1.19 \\
\hline T2-5 (3375) & 1.71 & 113 & 182 & 0.94 \\
\hline
\end{tabular}

\section{Reimers et al. (1992)}

A (581)
B (793)
$C(1181)$
$D(1443)$
E (1571)
F (1948)
G-88 (3324)

$\begin{array}{rr}18 & 0.3-0.5 \\ 11 & 0.2-0.5 \\ 26 & 0.3-0.5 \\ 37 & 0.5-1.0 \\ 50 & 0.6-0.9 \\ 75 & 0.8-1.2 \\ 120 & 0.9-2.0\end{array}$

Basins

$\begin{array}{llrrl}\text { SM }(905)^{*} & 0.36 & 5 & 229 & 0.16 \\ \text { Cat }(1300) & 0.46 & 19 & 76 & 0.61 \\ \text { TB }(1514) & 0.99 & 25 & 244 & 0.41 \\ \text { SCl }(2053) & 0.73 & 58 & 57 & 1.28 \\ \text { PE }(3707) & 0.63 & 131 & 22 & 2.87 \\ \text { SN }(1800) \# & 0.73 & 25 & 142 & 0.51 \\ \text { Cat }(1300) \dagger & 1.04 & 25 & 312 & 0.33\end{array}$

*Santa Monica oxygen flux data from Jahnke (1990).

\#San Nicolas oxygen flux data from Berelson et al. (1987a).

$\dagger$ These Catalina Basin oxygen flux and $\mathrm{BW} \mathrm{O}_{2}$ values from Archer and Devol (1992).

concentration of reactive organic carbon in the upper mm's of the sediment column. In applying this model to pore water profiles from the Washington shelf/slope and Catalina Basin, Archer and Devol (1992) found that $j_{\text {bulk }}$ remained constant between stations yet $R$ varied with water depth, relating to differences in the \% organic $\mathrm{C}$ within sediments. We find that the change in $R$ with depth or oxygen concentration is very small compared to differences in $R$ between cruise periods (Table 5). Although $R$ varied by a factor of 10 or greater, there was no difference in the weight fraction organic carbon in surficial sediments collected during CC I and CC II for sites at common depths (MLML unpub. data). Further, 

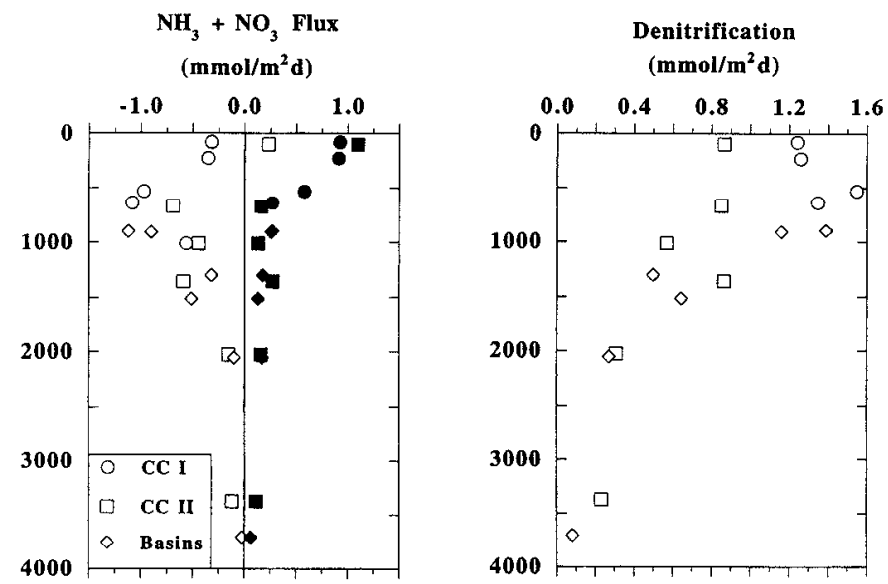

Figure 6. (a) The sum of measured ammonium and nitrate fluxes (open symbols) plotted vs. station depth $(\mathrm{m})$. The solid symbols represent the expected $\mathrm{NH}_{3}+\mathrm{NO}_{3}{ }^{-}$flux determined from $\mathrm{C}_{\mathrm{ox}}$ values and assuming Redfield stoichiometry. (b) Denitrification rates, defined as the difference between the expected and measured $\mathrm{N}$ flux.

sediments from the southern California borderland have a greater average wt. $\% \mathrm{C}_{\text {org }}$ than the central California sites, although the reactivities for CC II and Basin sites are similar. These results indicate that the average $\mathrm{wt} . \% \mathrm{C}_{\text {org }}$ in the upper mm's of the sediment column is not a good measure of the reactive carbon undergoing diagenesis.

The delivery of highly reactive organic matter to the sea floor may be related to seasonal climatological conditions. Surface water nitrate concentrations were much higher during the period covering the CC I cruise compared to the period of the CC II cruise (K. Johnson, MLML, unpub. data). Elevated values of primary productivity correspond with periods of enhanced surface water nitrate (F. Chavez, MBARI, pers. comm.). Smith et al. (1996) and Hammond et al. (1996) have documented the presence of chlorophyll-rich organic material on the sea floor in the central equatorial Pacific and its effect on oxygen uptake rates and kinetics. The average life time of this material is calculated to be $<1$ year (Hammond et al., 1996). Thus, the deposition of short-lived $C_{\text {org }}$ may modulate benthic oxygen and carbon fluxes on time scales of $<1$ year. Our results support the model of Archer and Devol (1992) whereby oxygen uptake is limited by the supply of labile $\mathrm{C}_{\text {org }}$ and the measurements of Smith et al. (1992) which document variability in oxygen uptake rates at a NE Pacific site. These results contrast with observations at the Bermuda time series site where Sayles $e t$ al. (1994) observe no coupling between $C_{\text {org }}$ rain and benthic fluxes.

e. Nitrogen fluxes and bottom water oxygen. Nowhere within the two regions studied do the sum of ammonia + nitrate fluxes from the sediment equal the quantity expected according to the amount of carbon oxidized and the Redfield ratio (Fig. 6a). This difference between observed and expected $\mathrm{N}$ fluxes may be due to a relatively large flux of DON (Burdige and Martens, 1988), a gross difference in C:N from Redfield stoichiometry, or it 
may reflect sedimentary denitrification. We assume DON fluxes represent a small fraction of the total N budget (Jahnke, 1990; Devol, 1991) and that the C:N of organic matter undergoing diagenesis cannot account for the large discrepancy between observed and predicted $\mathrm{N}$ fluxes. Even a substantially different value of $\mathrm{C}: \mathrm{N}$ in organic matter would not deny that sedimentary denitrification occurs throughout the entire transect. Our estimates of total denitrification are probably upper limits, especially for the regions above $500 \mathrm{~m}$.

Although nitrate uptake rates increase between 100 and $900 \mathrm{~m}$ (Fig. 3), the difference between the expected and observed $\mathrm{N}$ efflux does not show a depth dependence, indicating that total denitrification is not linearly related to nitrate uptake. Benthic chamber measurements of $\mathrm{N}_{2}$ fluxes from sediments on the Washington shelf (Devol, 1991) showed that the total dentrification rate, $3 \mathrm{mmol} / \mathrm{m}^{2} \mathrm{~d}$, was roughly 3 times greater than the rate of nitrate uptake, indicating the importance of sedimentary nitrification within the total denitrification cycle. The mean total denitrification rate for 2 stations on the central California shelf is $1 \mathrm{mmol} / \mathrm{m}^{2} \mathrm{~d}$, which is about twice the nitrate uptake rate. The rates of sea floor denitrification from the Washington (Devol, 1991) and central California shelves are comparable to rates of water column denitrification (per unit area) in the eastern tropical south Pacific (Codispoti and Packard, 1980). Thus, reactions within shelf sediments must be considered as a means of changing the ${ }^{15} \mathrm{~N} /{ }^{14} \mathrm{~N}$ in the nitrogen pool of the surface ocean. Even the relatively small denitrification rates determined for sediments between $1000-3500 \mathrm{~m}$ will have a large impact on global $\mathrm{N}$ budgets because of the large areal extent of this depth interval. Our data indicate that the budget of global denitrification compiled by Christensen et al. (1987) assigns a low estimate of sea floor diagenesis as a sink for fixed nitrogen, as suggested by Jahnke (1990) and Devol (1991).

Nitrate uptake, like oxygen uptake, shows a difference between sites sampled during CC I and CC II. In general, nitrate uptake shows an inverse relationship with bottom water oxygen concentration, although the pattern established from CC I is distinctly different from that shown by the CC II and Basins data (Fig. 7a). At depths $<500 \mathrm{~m}$ and $>2000 \mathrm{~m}$, the sediment is a sink for nitrate in spite of high oxygen concentrations. Nitrate uptake does not show a systematic relationship to nitrate concentration in bottom water (Fig. 7b). However, nitrate uptake is systematically related to the depth of oxygen penetration within these sediments (Fig. 7c). Oxygen penetration depth (depth $=h=J_{02} / R$ ), calculated from the reaction rates defined by Eq. (2), is predicted to vary between $0.1-2.9 \mathrm{~cm}$. In situ micro-electrode oxygen profiles from the central California region (Reimers et al., 1992) provide a check to these calculations and show reasonable agreement with the predicted values (Table 5). These results indicate that nitrate diffusion through the oxic sediment zone may be the regulating parameter controlling denitrification in marine sediments (Fig. 7d). Low bottom water oxygen concentration is not necessary to drive sedimentary denitrification provided that the magnitude of oxygen uptake is large.

f. Opal/carbon flux ratio. The production of siliceous and organic carbon particles in the surface ocean is linked by their biological origin. However, the time scales over which 

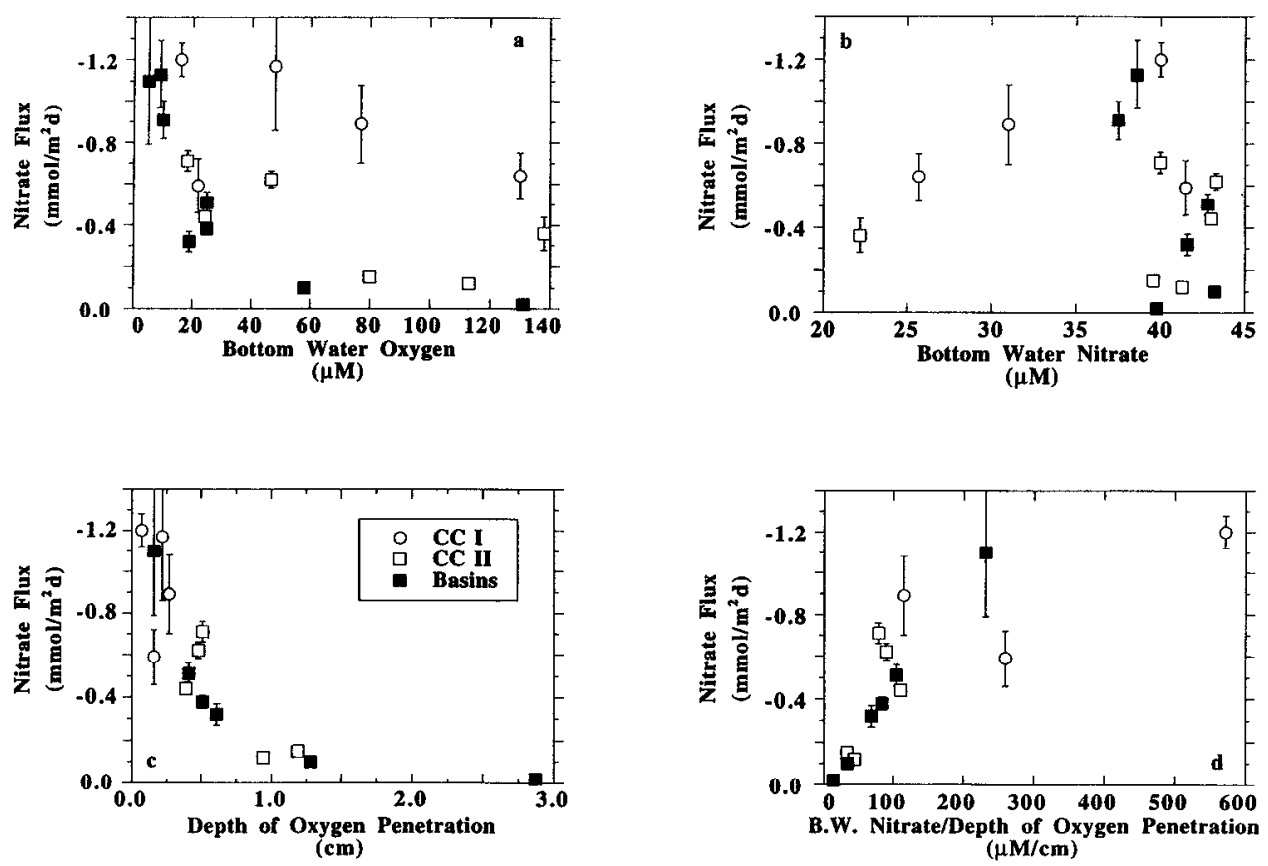

Figure 7. Nitrate fluxes determined with the benthic chambers plotted against: (a) bottom water oxygen concentration, (b) bottom water nitrate concentration, (c) model-determined depth of oxygen penetration, and (d) the ratio bottom water nitrate concentration:depth of oxygen penetration.

these biogenic materials are remineralized are thought to be quite different. Recent models utilizing measurements from the equatorial Pacific have shown that the residence time of biogenic silica on the sea floor may be divided between rapidly dissolving fractions and slowly dissolving fractions (McManus et al., 1995). As a test of this hypothesis, we compared the dissolved silica fluxes to $\mathrm{C}_{\mathrm{ox}}$.

Dissolved silica fluxes measured at stations located within the oxygen minimum zone during CC I were higher by a factor of 2 compared to measurements made during CC II (Fig. 2). This relationship was not due to bio-irrigation because, as discussed previously, radon data and the agreement between oxygen diffusive and chamber fluxes (Reimers $e t$ al., 1992) suggest that transport is dominated by diffusion. Sediment trap records from Monterey Bay indicate that 2-3 times more biogenic silica was falling through the water column during CC I as compared to the 1992 CC II cruise period (Pilskaln et al., 1996). Surface water measurements of elevated nitrate concentrations during the CC I cruise period (K. Johnson, MLML, unpub. data) suggest a linkage between upwelling, productivity, opal rain, and opal dissolution on the seafloor, to depths of $1000 \mathrm{~m}$. The coincidence of higher dissolution rates with higher opal rain rate suggests the there is a component of the opal rain with a fast rate constant for dissolution. 


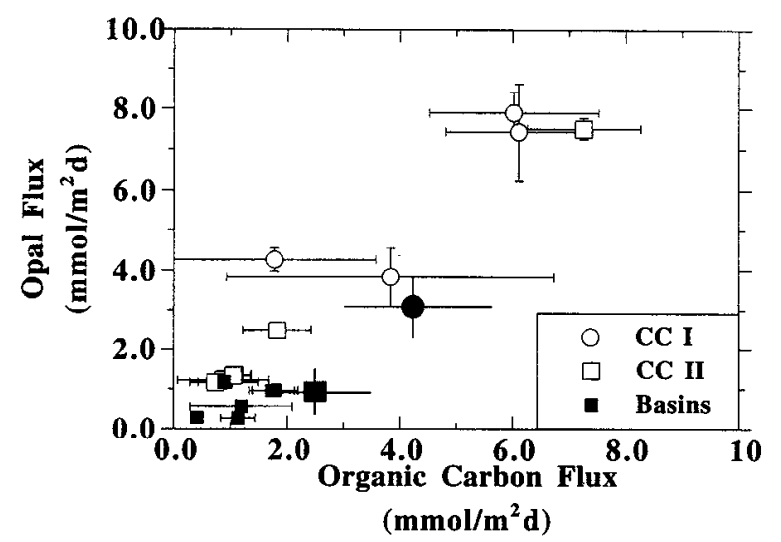

Figure 8. Dissolved silica flux vs. $\mathrm{C}_{\mathrm{ox}}$. The shaded circle represents the average opal and organic carbon rain rates determined from a sediment trap deployed at $450 \mathrm{~m}$ in Monterey Canyon (Pilskaln et al., 1996). The large shaded rectangle denotes the average opal and organic carbon rain rates determined from a sediment trap located in San Pedro Basin at $500 \mathrm{~m}$ (Thunell et al., 1994).

The depth dependence of $\mathrm{C}_{\mathrm{ox}}$ throughout the California margin transects is thought to reflect $\mathrm{C}_{\text {org }}$ degradation during rain from the surface ocean. If the attenuation of $\mathrm{C}_{\text {org }}$ fluxes with depth is due to its remineralization in the water column during settling, and opal has the same reactivity as $\mathrm{C}_{\text {org }}$, this could produce a constant relationship between $\mathrm{C}_{\mathrm{ox}}$ and biogenic silica dissolution rates throughout both central and southern California transects. $\mathrm{C}_{\mathrm{ox}}$ and opal dissolution rates are positively correlated $(r=0.95$, Fig. 8), which is consistent with the hypothesis that a fraction of the opal flux to the sea floor is reactive on the same time scale as organic carbon. The mean $\mathrm{C}_{\mathrm{ox}}$ :opal dissolution flux for the entire region is $0.8 \pm 0.2$. This ratio is comparable to the rain ratio $(1.2 \pm 0.5)$ of a trap located at a depth of $450 \mathrm{~m}$ in Monterey Bay (Pilskaln et al., 1996), but these values are less than the $\mathrm{C}_{\text {org }}$ :opal rain ratio of a trap located at a depth of $500 \mathrm{~m}$ in San Pedro Basin, $2.7 \pm 0.7$ (Thunell et al., 1994). However, the trap located within San Pedro Basin may be influenced by the input of organic carbon from the basin walls, hence elevating the $\mathrm{C}_{\mathrm{org}}$ :opal rain ratio.

In two borderland basins, the fraction of biogenic silica that ends up buried in the sediments is about $10 \%$ (Berelson et al., 1987a). This is roughly the same fraction preserved in the equatorial Pacific region between $5 \mathrm{~N}$ and $\mathrm{S}$ at a depth of $4500 \mathrm{~m}$ (McManus et al., 1995). However, in the equatorial Pacific, carbon preservation represents $<1 \%$ of the rain to the sea floor, whereas organic carbon has a burial efficiency of about $50 \%$ in the basins. This implies that the process of down-slope transport of older, refractory $\mathrm{C}_{\mathrm{org}}$ is not effective in moving less reactive opal into the center of the basins.

g. $\mathrm{TCO}_{2} /$ Alkalinity flux ratio. The ratio of $\mathrm{TCO}_{2}$ to carbonate alkalinity fixes the $\mathrm{pH}$ within the ocean and the speciation between dissolved $\mathrm{CO}_{2}, \mathrm{HCO}_{3}{ }^{-}$and $\mathrm{CO}_{3}{ }^{2-}$. Benthic flux is an important component of the deep ocean budgets for these species (Berelson et al., 1994). Thus, the processes which regulate their flux ratio: carbonate dissolution due to undersatu- 


\section{$\mathrm{TCO}_{2}$ :Alk Flux Ratio}

(mmol/meq)

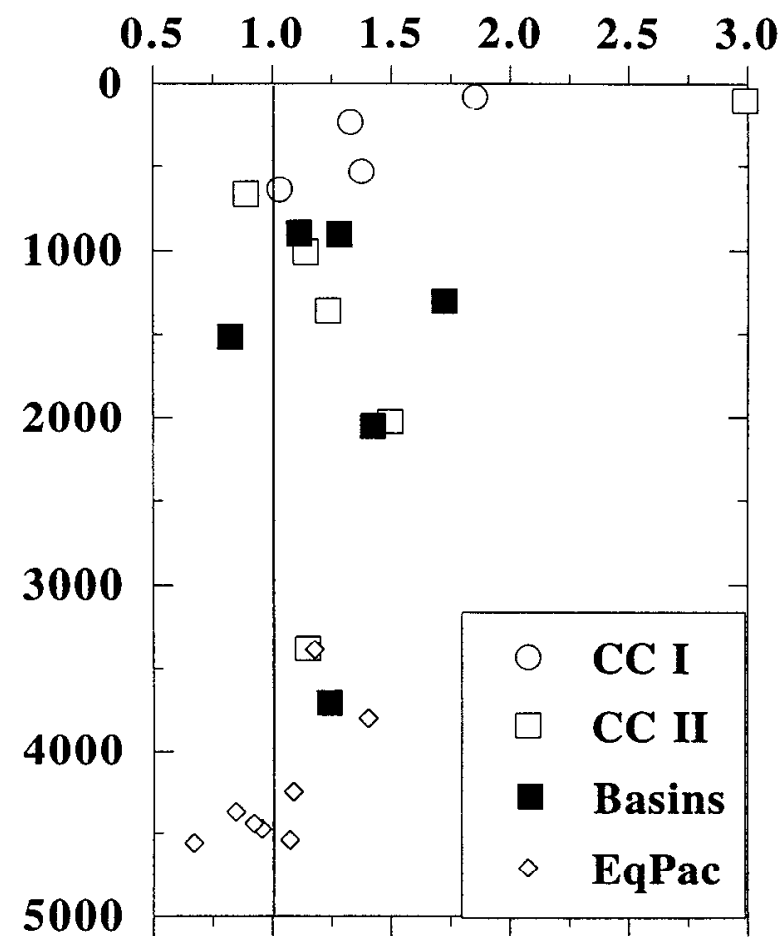

Figure 9. The ratio of $\mathrm{TCO}_{2}$ flux to total alkalinity flux measured with the USC benthic chambers from sites off central California, southern California Basins, and from the eastern equatorial Pacific (data from Hammond et al., 1996).

ration, carbonate dissolution driven by organic carbon oxidation, and the relative proportions of aerobic and anaerobic oxidation of $\mathrm{C}_{\mathrm{org}}$, are important in regulating their oceanic ratio.

The profile of $\mathrm{TCO}_{2} /$ alkalinity flux ratio with depth through both margin transects (Fig. 9) indicates that benthic processes taking place in the core of the oxygen minimum zone produce alkalinity fluxes that equal or exceed $\mathrm{TCO}_{2}$ fluxes. Hence, in this portion of the ocean, sedimentary processes act to raise the average $\mathrm{pH}$ of the water column. The benthic flux of alkalinity in these regions is supplied primarily from net sulfate reduction. Very little to no $\mathrm{CaCO}_{3}$ dissolution takes place within the sediments underlying the oxygen minimum zone (Fig. 4). Results from work within the equatorial Pacific region (Berelson et al., 1994) indicate that at depths below $4200 \mathrm{~m}$, the sediments are also contributing alkalinity in excess of $\mathrm{TCO}_{2}$. Within these regions, $\mathrm{CaCO}_{3}$ dissolution due to $\mathrm{C}_{\mathrm{ox}}$ and water column undersaturation provides the buffering effect. 
Berelson et al. (1994) predicted the benthic input of alkalinity to the Pacific Ocean using a model for oxygen uptake and carbonate dissolution. They found that if $\mathrm{CaCO}_{3}$ dissolution is the only source of alkalinity to the Pacific Basin $(>1000 \mathrm{~m})$, there is agreement to within $15 \%$ of this sediment-based alkalinity budget and a hydrographic box-model budget (Broecker and Peng, 1987). The results of this study indicate that Berelson et al. (1994) have underestimated the sea floor contribution of alkalinity to the $1000-2000 \mathrm{~m}$ depth zone because they did not take into account sulfate reduction. However, the difference between the carbonate dissolution predicted alkalinity flux $\left(0.8 \mathrm{meq} / \mathrm{m}^{2} \mathrm{~d}\right)$ and the measured flux (1.2 $\mathrm{meq} / \mathrm{m}^{2} \mathrm{~d}$, from Fig. 4) amounts to a small correction $(<2 \%)$ to the Pacific Basin budget for alkalinity. The sediment model predicts a $\mathrm{CaCO}_{3}$ dissolution rate of $0.4 \mathrm{mmol} / \mathrm{m}^{2} \mathrm{~d}$ for the depth zone $3000-4000 \mathrm{~m}$ and the limited data from this study support that value (Fig. 4). Hence, the results obtained in this study are consistent with the conclusion of Berelson et al. (1994) that sea floor processes can account for all the alkalinity in the deep Pacific.

\section{Summary and conclusions}

Benthic chamber measurements of the reactants and products involved with biogenic matter diagenesis (oxygen, ammonium, nitrate, silicate, phosphate, $\mathrm{TCO}_{2}$, and alkalinity) define fluxes of these solutes into and out of the sediments off southern and central California. These measurements, including two transects through the oxygen minimum zone off central California, indicate a general concordance in rates of biogenic matter remineralization.

(1) Off central and southern California, benthic fluxes measured with the USC benthic chamber, BECI (Jahnke and Christiansen, 1989), the Bottom Lander (Bender et al., 1989) and the FVGR (Smith et al., 1979) yield generally similar patterns of flux vs. depth.

(2) Although there is some temporal variability, the average profile of benthic $C_{\text {ox }}$ as a function of depth between 100 and $3500 \mathrm{~m}$ off central California can be well fit with the same function Martin et al. (1987) use to describe carbon rain through the water column in this region. Carbon burial in the slope sediments accounts for $<20 \%$ of the carbon rain, whereas burial on the shelf accounts for about $50 \%$ of the rain. Two, multi-year records of sediment trap collections suggest that carbon supply from vertical rain can just meet sedimentary carbon oxidation demand.

(3) There is not enough carbon raining through the upper water column to support the oxidation and burial of organic carbon in the basins off southern California. Older carbon, derived from the basin slopes is inferred to supply the carbon buried in basin sediments. The efficiency of carbon burial off southern California is about $50 \%$ compared to $13 \%$ off central California. Lateral transport and focusing of refractory carbon within the central basin is proposed to account for this difference. Productivity and rain of organic carbon from the surface ocean can support the measured rates of $\mathrm{C}_{\mathrm{ox}}$ within the basins and a site on the slope at $3700 \mathrm{~m}$. 
(4) The reactivity of sediment with respect to oxygen uptake is variable on the seasonal scale and is not correlated with bulk weight percent $\mathrm{C}_{\mathrm{org}}$ in surface sediments. This result indicates that oxygen uptake rates are very sensitive to a small fraction of the total carbon within the sediments.

(5) Oxygen uptake rates and bottom water oxygen concentrations combine to define the depth of oxygen penetration within the sediments. Nitrate uptake rates are very sensitive to this parameter. Overall denitrification rates, based of the comparison between expected $\mathrm{N}$ fluxes and the sum of $\mathrm{NH}_{3}+\mathrm{NO}_{3}{ }^{-}$fluxes, indicate that denitrification is occurring within the sediments off California between 100 and $3500 \mathrm{~m}$. The magnitude of denitrification is roughly the same between 100 and $900 \mathrm{~m}$, about $1.2 \mathrm{mmol} \mathrm{N} / \mathrm{m}^{2} \mathrm{~d}$. Nitrate uptake vs. depth does not reflect bottom water oxygen concentration directly but rather the balance between $\mathrm{C}_{\mathrm{ox}}$ and bottom water nitrate and oxygen concentrations.

(6) The dissolution rate of biogenic silica on the sea floor is variable in time and space. Our results are consistent with the hypothesis that opal productivity in coastal margin settings is dominated by a readily dissolvable form. The ratio of carbon oxidized to opal dissolved is constant $(0.8 \pm 0.2)$ within the coastal transect region through a wide range of depths.

(7) Only in the oxygen minimum zone is the $\mathrm{TCO}_{2}$ to alkalinity flux ratio $<1(\mu \mathrm{M} / \mu \mathrm{eq})$, identifying this zone as a region where sedimentary processes contribute to raising oceanic $\mathrm{pH}$. Carbonate dissolution rates have been calculated based on an alkalinity budget approach, and in spite of large uncertainties, there appears to be maxima in carbonate dissolution just above and below the oxygen minimum zone $\left(0.2-2.0 \mathrm{mmol} \mathrm{CaCO}_{3} / \mathrm{m}^{2} \mathrm{~d}\right)$ and a minima within this zone (no dissolution). Carbonate dissolution and alkalinity flux measurements are consistent with model predictions (Berelson et al., 1994) which allow the sea floor to account for all the alkalinity within the deep Pacific Ocean basin.

Acknowledgments. Support for this research was provided by N.S.F. grants to W.B., K.J. and K.C. We'd like to thank Ginger Flrod, Jim Gardner, Doug Hammond, Helen Iams, Jocelyn Nowicki, Sara Tanner, Tom Van Tress, and the captains and the crews of R.V. Point Sur and R.V. New Horizon for their assistance. We acknowledge the thoughtful criticism of two anonymous reviewers.

\section{REFERENCES}

Aller, R. C. 1994. Bioturbation and remineralization of sedimentary organic matter: effects of redox oscillation. Chem. Geol., 114, 331-345.

Anderson, R. F., G. T. Rowe, P. F. Kemp, S. Trumbore and P. E. Biscaye. 1994. Carbon budget for the mid-slope depocenter of the Middle Atlantic Bight. Deep-Sea Res., 41, 669-703.

Archer, D. and A. Devol. 1992. Benthic oxygen fluxes on the Washington shelf and slope: A comparison of in situ microelectrode and chamber flux measurements. Limnol. Oceanog., 37, $614-629$.

Bauer, J. E., C. E. Reimers, E. R. M. Druffel and P. M. Williams. 1995. Isotopic constraints on carbon exchange between deep ocean sediments and sea water. Nature, 373, 686-689.

Bender, M., R. Jahnke, R. Weiss, W. Martin, D. T. Heggie, J. Orchardo and T. Sowers. 1989. Organic carbon oxidation and benthic nitrogen and silica dynamics in San Clemente Basin, a continental borderland site. Geochim. Cosmochim. Acta, 53, 685-698. 
Berelson, W. M. 1991. The flushing of two deep sea basins, southern California borderland. Limnol. Oceanogr., 36, 1150-1166.

Berelson, W. M. and D. E. Hammond. 1986. The calibration of a new free vehicle benthic flux chamber for use in the deep-sea. Deep-Sea Res., 33, 139-1454.

Berelson, W. M., D. E. Hammond and G. Cutter. 1990. In situ measurements of calcium carbonate dissolution in deep-sea sediments. Geochim. Cosmo. Acta, 54, 3013-3020.

Berelson, W. M., D. E. Hammond and K. S. Johnson. 1987a. Benthic fluxes and the cycling of biogenic silica and carbon in the two southern California Borderland Basins. Geochim. Cosmochim. Acta, 51, 1345-1363.

Berelson, W. M., D. E. Hammond, J. McManus and T. E. Kilgore. 1994. Dissolution kinetics of calcium carbonate in Equatorial Pacific sediments. Global Biogeochem. Cycles, 8, 219-235.

Berelson, W. M., D. E. Hammond, K. L. Smith, R. A. Jahnke, A. H. Devol, K. R. Hinga, G. T. Rowe and F. Sayles. 1987b. In situ benthic flux measurement devices: bottom lander technology. Marine Technology Society J., 2l, 26-32.

Biscaye, P. E., C. N. Flagg and P. G. Falkowski. 1994. The shelf edge exchange processes experiment, SEEP-II: an introduction to hypotheses, results and conclusions. Deep-Sea Res., 41 , $231-252$

Brandsma, D., S. P. Lund and T. L. Henyey. 1989. Paleomagnetism of late Quaternary marine sediments from Santa Catalina Basin, California continental borderland. Jour. Geophys. Res., 94, 547-564.

Broecker, W. S. and T.-H. Peng. 1987. The role of $\mathrm{CaCO}_{3}$ compensation in the glacial to interglacial atmospheric $\mathrm{CO}_{2}$ change. Global Biogeochem. Cycles, 1, 15-29.

Bruland, K. W., R. P. Franks, W. L. Landing and A. Soutar. 1981. Southern California inner basin sediment trap calibration. Earth and Planet. Sci. Lett., 53, 400-408.

Burdige, D. J. 1991. The kinetics of organic matter mineralization in anoxic marine sediments. J. Mar. Res., 49, 727-761.

Burdige, D. J., M. J. Alperin, J. Homstead and C. Martens. 1992. The role of benthic fluxes of dissolved organic carbon in oceanic and sedimentary carbon cycling. Geophys. Res. Lett., 19, 1851-1854.

Burdige, D. J. and C. Martens. 1988. Biogeochemical cycling in an organic rich marine basin. 10. The role of amino acids in sedimentary carbon and nitrogen cycling. Geochim. Cosmochim. Acta, $52,1571-1584$.

Cai, W. J. and F. L. Sayles. 1996. Oxygen penetration depths and fluxes in marine sediments. Mar. Chem., 52, 123-131.

Canfield, D. E. 1994. Factors influencing organic carbon preservation in marine sediments. Chem. Geol., 114, 315-329.

Christensen, C. J., D. S. Gorsline, D. E. Hammond and S. P. Lund. 1994. Non-annual laminations and expansion of anoxic basin-floor conditions in Santa Monica Basin, California borderland, over the past four centuries. Mar. Geol., 116, 399-418.

Christensen, J. P., J. W. Murray, A. H. Devol and L. A. Codispoti. 1987. Denitrification in continental shelf sediments has major impact on the oceanic nitrogen budget. Global Biogeochem. Cycles, 1, 97-116.

Codispoti, L. A. and T. T. Packard. 1980. Denitrification rates in the eastern tropical South Pacific. J. Mar. Res., 38, 453-477.

Devol, A. 1991. Direct measurement of nitrogen gas fluxes from continental shelf sediments. Nature, 349, 319-321.

Eganhouse, R. P. and M. I. Venkatesan. 1993. Chemical oceanography and geochemistry, in Ecology of the Southern California Bight, M. D. Dailey, D. J. Reish and J. W. Anderson, eds., Univ. of California Press, 71-189. 
Eppley, R. W. 1992. Chlorophyll, photosynthesis and new production in the Southern California Bight. Prog. Oceanogr., 30, 117-150.

Gorsline, D. S. 1992. The geological setting of Santa Monica and San Pedro Basins, California continental borderland. Prog. Oceanogr., 30, 1-36.

Hales, B., S. Emerson and D. Archer. 1994. Respiration and dissolution in the sediments of the western North Atlantic: estimates from models of in situ microelectrode measurements of porewater oxygen and pH. Deep-Sea Res., 41, 695-719.

Hammond, D. E., J. McManus, W. M. Berelson, T. E. Kilgore and R. H. Pope. 1996. Degradation of organic material in the Equatorial Pacific Region: Stoichiometry and kinetics. Deep-Sea Res., (in press)

Hickey, B. 1992. Circulation over the Santa Monica-San Pedro Basin and shelf. Prog. Oceangr., 30, 37-115.

Huh, C.-A., B. P. Finney and J. K. Stull. 1992. Anthropogenic inputs of several heavy metals to nearshore basins off Los Angeles. Prog. Oceanogr., 30, 335-351.

Huh, C.-A., L. R. Small, S. Miemnil, B. P. Finney, B. M. Hickey, N. B. Kachel, D. S. Gorsline and P. M. Williams. 1990. Sedimentation dynamics in the Santa Monica-San Pedro Basin off Los Angeles: Radiochemical, sediment trap, and transmissometer studies. Cont. Shelf Res., 10, 137-164.

Jackson, G. A., R. Azam, A. F. Carlucci, R. W. Eppley, B. Finney, D. S. Gorsline, G. Hickey, C.-A. Huh, R. A. Jahnke, I. R. Kaplan, M. R. Landry, L. F. Small, M. I. Venkatesan, P. M. Williams and K. M. Wong. 1989. Elemental cycling and fluxes off the coast of southern California. EOS, Trans. Am. Geophys. Union, 70, 146-155.

Jahnke, R. A. 1990. Early diagenesis and recycling of biogenic debris at the sea floor. Santa Monica Basin, California. J. Mar. Res., 48, 413-438.

Jahnke, R. A. and M. B. Christiansen. 1989. A free-vehicle benthic chamber instrument for sea floor studies. Deep-Sea Res., 36, 625-637.

Jahnke, R. A. and G. A. Jackson. 1987. Role of sea floor organisms in oxygen consumption in the deep North Pacific ocean. Nature, 329, 621-623.

Jahnke, R. A., C. E. Reimers and D. B. Craven. 1990. Intensification of recycling of organic matter at the sea floor near ocean margins. Nature, 348, 50-54.

Johnson, K. S., W. M. Berelson, K. H. Coale, V. A. Elrod, W. R. Fairey, H. D. Iams, T. E. Kilgore, and J. N. Nowicki. 1992. Manganese flux from continental margin sediments in a transect through the oxygen minimum. Science, 257, 1242-1245.

Keil, R. G., E. Tsamakis, C. Gor Fuh, J. C. Giddings and J. I. Hedges. 1994. Mineralogical and textural controls on the organic composition of coastal marine sediments: Hydrodynamic separation using SPLITT-fractionation. Geochim. Cosmochim. Acta, 58, 879-893.

Landry, M. R., W. K. Peterson and C. C. Andrews. 1992. Particulate flux in the water column overlying Santa Monica Basin. Prog. Oceanogr., 30, 167-195.

Lee, C. 1992. Controls on organic carbon preservation: The use of stratified water bodies to compare intrinsic rates of decomposition in oxic and anoxic systems. Geochim. Cosmochim. Acta, 56, 3323-3335.

Leslie, B. W., D. E. Hammond, W. M. Berelson, and S. P. Lund. 1990. Diagenesis in anoxic sediments from the California Continental Borderland and its influence on iron, sulfur, and magnetite behavior. J. Geophys. Res., 95, 4453-4470.

Martin, J. H., G. A. Knauer, D. M. Karl and W. W. Broenkow. 1987. Vertex: Carbon cycling in the northeast Pacific. Deep-Sea Res., 34, 267-285.

Martin, W. R., M. Bender, M. Leinen and J. Orchardo. 1991. Benthic organic carbon degradation and biogenic silica dissolution in the central equatorial Pacific. Deep-Sea Res., 38, 1481-1516. 
Martin, W. R. and D. C. McCorkle. 1994. Dissolved organic carbon in continental margin sediments: An assessment of the relative rates of carbon oxidation to $\mathrm{CO}_{2}$ and net DOC production. EOS, Trans. Amer. Geophys. Union, 323.

Mayer, L. M. 1994a. Relationships between mineral surfaces and organic carbon concentrations in soils and sediments. Chem. Geol., 114, 347-363.

— 1994b. Surface area control of organic carbon accumulation in continental shelf sediments. Geochim. Cosmochim. Acta, 58, 1271-1284.

McManus, J., W. M. Berelson, D. E. Hammond, T. E. Kilgore, D. J. DeMaster, O. G. Ragueneau and R. Collier. 1995. Early diagenesis of biogenic opal: Dissolution rates, kinetics, and paleoceanographic implications. Deep-Sea Res., 42, 871-903.

McManus, J., W. M. Berelson, T. E. Kilgore, K. Coale, K. Johnson, D. Colbert, T. Coley, V. Elrod, E. Kingsley, J. Nowicki and H. Zamzow. 1994. Organic carbon to phosphorus regeneration ratios in eastern boundary continental margin sediments. EOS, Trans. Amer. Geophys. Union, 326.

Middelburg, J. J. 1989. A simple model for organic matter decomposition in marine sediments. Geochim. Cosmochim. Acta, 53, 1577-1581.

Nelson, J. R., J. R. Beers, R. W. Eppley, J. A. Jackson, J. J. McCarthy and A. Soutar. 1987. A particle flux study in the Santa Monica-San Pedro Basin off Los Angeles: particle flux, primary production, and transmissometer survey. Cont. Shelf Res., 7, 307-328.

Pilskaln, C. H., J. B. Paduan, F. B. Chavez, R. Y. Anderson and W. Berelson. 1996. Carbon export and regeneration in the coastal upwelling system of Monterey Bay, central California. J. Mar. Res., 54, (in press).

Reimers, C. E., K. M. Fischer, R. Merewether, K. L. Smith, Jr. and R. A. Jahnke. 1986. Oxygen microprofiles measured in situ in deep ocean sediments. Nature, 320, 741-744.

Reimers, C. E., R. A. Jahnke and D. C. McCorkle. 1992. Carbon fluxes and burial rates over the continental slope and rise off central California with implications for the global carbon cycle. Global Biogeo. Cycles, 6, 199-224.

Reimers, C. E. and K. L. Smith. 1986. Reconciling measured and predicted fluxes of oxygen across the deep sea sediment-water interface. Limnol. Oceanogr., 31, 305-318.

Risgaard-Petersen, N., S. Rysgaard, L., P. Nielsen and N. P. Revsbech. 1994. Diurnal variation of denitrification and nitrification in sediments colonized by benthic microphytes. Limnol. Oceanogr., 39, 573-579.

Rowe, G. T., G. S. Boland, W. C. Phoel, R. F. Anderson and P. E. Biscaye. 1994. Deep-sea floor respiration as an indication of lateral inpul of biogenic detritus from continental margins. Deep-Sea Res., 41, 657-668.

Savrda, C. E., D. J. Bottjer and D. S. Gorsline. 1984. Development of a comprehensive oxygen deficient marine biofacies model: Evidence from Santa Monica, San Pedro and Santa Barbara Basins, California continental borderland. Am. Assoc. Pet. Geol. Bull., 68, 1179-1192.

Sayles, F. L., W. R. Martin and W. G. Deuser. 1994. Response of benthic oxygen demand to particulate organic carbon supply in the deep sea near Bermuda. Nature, 371, 686-689.

Schwalbach, J. R. and D. S. Gorsline. 1985. Holocene sediment budgets for the basins of the California continental borderland. J. Sed. Pet., 55, 829-842.

Shaw, T. J., J. M. Gieskes and R. A. Jahnke. 1990. Early diagenesis in differing depositional environments: The response of transition metals in pore water. Geochim. Cosmochim. Acta, 54, 1233-1246.

Smith, C. R., D. J. Hoover, S. E. Doan, S. P. Garner and R. II. Pope. 1996. Phytodetritus at the abyssal seafloor across $10^{\circ}$ of latitude in the central equatorial Pacific. Deep-Sea Res., (in press)

Smith, K. L. 1987. Food energy supply and demand: A discrepancy between particulate organic carbon flux and sediment community oxygen consumption in the deep ocean. Limnol. Oceanogr., $32,201-220$. 
1989. Short time-series measurements of particulate organic carbon flux and sediment community oxygen consumption in the North Pacific. Deep-Sea Res., 36, 1111-1119.

Smith, K. L., R. J. Baldwin and P. M. Williams. 1992. Reconciling particulate organic carbon flux and sediment community oxygen consumption in the deep N. Pacific. Nature, 359, 313-316.

Smith, K. L., A. F. Carlucci, R. A. Jahnke and D. B. Craven. 1987. Organic carbon mineralization in the Santa Catalina Basin: Benthic boundary layer metabolism. Deep-Sea Res., 34, 185-212.

Smith, K. L., R. S. Kaufmann and R. J. Baldwin. 1994. Coupling of near bottom pelagic and benthic processes at abyssal depths in the eastern North Pacific Ocean. Limnol. Oceanogr., 39, 1101-1118.

Smith, K. L., M. B. Laver and N. O. Brown. 1983. Sediment community oxygen consumption and nutrient exchange in the central and eastern North Pacific. Limnol. Oceanogr., 28, 882-898.

Smith, K. L., G. A. White and M. B. Laver. 1979. Oxygen uptake and nutrient exchange of sediments measured in situ using a free vehicle grab respirometer. Deep-Sea Res., 26, 337-346.

Tengberg, A., F. DeBovee, P. Hall, W. Berelson, D. Chadwick, G. Ciceri, P. Crassous, A. Devol, S. Emerson, J. Gage, R. Glud, F. Graziottini, J. Gundersen, D. Hammond, W. Helder, K. Hinga, O. Holby, R. Jahnke, A. Khripounoff, S. Lieberman, V. Nuppenau, O. Pfannkuche, C. Reimers, G. Rowe, A. Sahami, F. Sayles, M. Schurter, D. Smallman, B. Wehrli, and P. DeWilde. 1995. Benthic chamber and profiling landers in oceanography-A review of design, technical solutions and functioning. Prog. Oceanogr., 25, 253-294.

Thunell, R. C., C. H. Pilskaln, E. Tappa and L. R. Sautter. 1994. Temporal variability in sediment fluxes in the San Pedro Basin, Southern California Bight. Cont. Shelf Res., 14, 333-352.

Treguer, P., D. M. Nelson, A. J. Van Bennekom, D. J. DeMaster, A. Leynaert and B. Queguiner. 1995. The silica balance in the world ocean: A reestimate. Science, 268, 375-379.

Ullman, W. J. and R. C. Aller. 1982. Diffusion coefficients in nearshore marine sediments. Limnol. Oceanogr., 27, 552-556.

Ventkatessen, M. I. and I. R. Kaplan. 1992. Vertical and lateral transport of organic carbon and the carbon budget in Santa Monica Basin, California. Prog. Oceanogr., 30, 291-312.

Westrich, J. T. and R. A. Berner. 1984. The role of sedimentary organic matter in bacterial sulfate reduction: The $\mathrm{G}$ model tested. Limnol. Oceanogr., 29, 236-249.

Williams, P. M., K. J. Roberson, A. Soutar, S. M. Griffin and E. R. M. Druffel. 1992. Isotopic signatures as tracers of sources and cycling of soluble and particulate organic matter in the Santa Monica Basin, California. Prog. Oceanogr., 30, 253-290.

Received: 12 June, 1995; revised: 23 January, 1996. 